\title{
Assessing the influence of sea surface temperature and arctic sea ice cover on the uncertainty in the boreal winter future climate projections
}

\author{
Ho-Nam Cheung ${ }^{1,2,3} \cdot$ Noel Keenlyside ${ }^{3,4,5,6} \cdot$ Torben Koenigk $^{7,8}$. Shuting Yang ${ }^{9} \cdot$ Tian Tian $^{9} \cdot$ Zhiqing Xu $^{10}$. \\ Yongqi Gao ${ }^{5,10} \cdot$ Fumiaki Ogawa $^{3,4,11} \cdot$ Nour-Eddine Omrani $^{3,4}$. Shaobo Qiao ${ }^{1,2} \cdot$ Wen Zhou $^{12}$
}

Received: 29 March 2021 / Accepted: 1 January 2022 / Published online: 20 January 2022

(c) The Author(s) 2022, corrected publication 2022

\begin{abstract}
We investigate the uncertainty (i.e., inter-model spread) in future projections of the boreal winter climate, based on the forced response of ten models from the CMIP5 following the RCP8.5 scenario. The uncertainty in the forced response of sea level pressure (SLP) is large in the North Pacific, the North Atlantic, and the Arctic. A major part of these uncertainties (31\%) is marked by a pattern with a center in the northeastern Pacific and a dipole over the northeastern Atlantic that we label as the Pacific-Atlantic SLP uncertainty pattern $\left(\mathrm{PA}_{\Delta \mathrm{SLP}}\right)$. The $\mathrm{PA}_{\Delta \mathrm{SLP}}$ is associated with distinct global sea surface temperature (SST) and Arctic sea ice cover (SIC) perturbation patterns. To better understand the nature of the PA ${ }_{\triangle S L P}$, these SST and SIC perturbation patterns are prescribed in experiments with two atmospheric models (AGCMs): CAM4 and IFS. The AGCM responses suggest that the SST uncertainty contributes to the North Pacific SLP uncertainty in CMIP5 models, through tropical-midlatitude interactions and a forced Rossby wavetrain. The North Atlantic SLP uncertainty in CMIP5 models is better explained by the combined effect of SST and SIC uncertainties, partly related to a Rossby wavetrain from the Pacific and air-sea interaction over the North Atlantic. Major discrepancies between the CMIP5 and AGCM forced responses over northern high-latitudes and continental regions are indicative of uncertainties arising from the AGCMs. We analyze the possible dynamic mechanisms of these responses, and discuss the limitations of this work.
\end{abstract}

Keywords Climate change $\cdot$ Uncertainty in climate projections $\cdot$ Winter climate $\cdot$ Aleutian low $\cdot$ Icelandic low

Ho-Nam Cheung

zhanghlan5@mail.sysu.edu.cn

1 School of Atmospheric Sciences, Sun Yat-Sen University, Southern Marine Science and Engineering Guangdong Laboratory (Zhuhai), Zhuhai, China

2 Guangdong Province Key Laboratory for Climate Change and Natural Disaster Studies, Sun Yat-Sen University, Zhuhai, China

3 Bjerknes Centre for Climate Research, University of Bergen, Bergen, Norway

4 Geophysical Institute, University of Bergen, Bergen, Norway

5 Nansen Environmental and Remote Sensing Center, Bergen, Norway

6 A.M. Obukhov Institute of Atmospheric Physics, RAS, Moscow, Russia
7 Swedish Meteorological and Hydrological Institute, Norrköping, Sweden

8 Bolin Centre for Climate Research, Stockholm University, Stockholm, Sweden

9 Danish Meteorological Institute, Copenhagen, Denmark

10 Nansen-Zhu International Research Centre, Institute of Atmospheric Physics, Chinese Academy of Sciences, Beijing, China

11 Graduate School of Science, Hokkaido University, Sapporo, Japan

12 Department of Atmospheric and Oceanic Sciences, Institute of Atmospheric Sciences, Fudan University, Shanghai, China 


\section{Introduction}

There is great concern on if and how the intensity and location of large-scale near-surface circulation features (e.g., sea level pressure, SLP, near the Aleutian low and the Icelandic low) and their associated high-impact weather will change with global warming. Climate models consistently simulate a significant and systematic increase in surface air temperature in the high emission scenarios. Still, they show a large discrepancy in the magnitude of global warming because of their different climate sensitivity (Andrew et al. 2012; Vial et al. 2013; Hu et al. 2017, 2020). The magnitude of warming also shows discrepancies with latitude and altitude associated with differences in the hemispheric temperature gradient and the large-scale atmospheric circulation features. In particular, there is a large disagreement in terms of the magnitude and sign in future projections of midlatitude atmospheric circulation for the end of this century, even when considering only the dominant external forcing (Shepherd 2014; Cheung et al. 2018). To better interpret and constraint future climate projections, we need to understand the dynamics underlying the uncertainty in future projections of large-scale atmospheric circulation.

Tropical upper-tropospheric warming and Arctic lower tropospheric warming (also called Arctic amplification) are two prominent temperature responses to global warming. Specifically, tropical upper-tropospheric warming accompanies an increase in the upper-tropospheric equator-topole temperature gradient, which would cause an increase in the midlatitude zonal wind speed, and a poleward shift in the jet stream and storm tracks (Yin 2005; Chang et al., 2012; Barnes and Polvani 2013). On the other hand, Arctic lower tropospheric warming accompanies a decrease in the equator-to-pole temperature gradient. This would cause a reduction in the midlatitude zonal wind speed, and an equatorward shift in the jet stream due to the thermal wind balance (Harvey et al. 2015). In CMIP3 and CMIP5 models, the uncertainty in future projections of jet stream and storm tracks is partly related to these competing effects (Barnes and Screen 2015; Shaw et al. 2016; Screen et al. 2018). While the model-mean global warming response tends to be a poleward shift of the jet stream, the inter-model spread in the projected change in zonal wind speed is linked to the spread in Arctic amplification, tropical warming, and the strength of stratospheric polar vortex (Manzini et al. 2014; Barnes and Screen 2015; Zappa and Shepherd 2017; Cheung et al. 2018; Oudar et al. 2020). In particular, a stronger Arctic amplification tends to be associated with a weaker and southward shift of the jet stream; this is opposite in sign to the mean change (Deser et al. 2015; Yim et al. 2016).

Previous studies have related the uncertainty in future projections of regional atmospheric circulation to the uncertainty in future projections of sea surface temperature (SST) and Arctic sea ice cover (SIC). Over the North Pacific, climate models tend to project a deeper and a northward expansion of the Aleutian low in the future (Gan et al. 2017; see also Fig. 1a). However, future projections of the southeastern and northwestern parts of the Aleutian low have a large uncertainty that is strongly linked to the zonal SST gradient in the equatorial Pacific (an El Niño-like mean state; Gan et al. 2017). Besides the El Niño-like signal, the uncertainty in future projections of the Aleutian low is related to the land-sea thermal contrast between the Asian continent and the Pacific Ocean, and the associated zonal pressure gradient between the Siberian high and the Aleutian low (Gan et al. 2017). Choi et al. (2016) found that the uncertainty in future projections of SLP over the eastern North Pacific is related to a Pacific Decadal Oscillation (PDO)-like SST signal, where the SST anomalies are strongest in the midlatitudes.

Over the North Atlantic, the multi-model mean (MME) of future climate projections indicates a slight positive trend of the wintertime North Atlantic Oscillation (NAO) and a northeastward extension of the storm tracks (Bader et al. 2011; Woollings et al. 2012; Lau and Ploshay 2013), but these projections have a large uncertainty. Some studies suggest that this uncertainty is driven by remote forcing (Harvey et al. 2015; Ciasto et al. 2016), with relatively little impact from local SST in these models (Hand et al. 2019), whereas some studies suggest local SST contribute to the uncertainty (Gervais et al. 2019). On one hand, the uncertainty in the future projections of Arctic SIC causes uncertainty in the lower tropospheric equator-to-pole temperature gradient and the North Atlantic storm tracks (Harvey et al. 2015). The decline in Arctic SIC also favors a negative NAO-like response and a higher SLP response over the northern Eurasia (Peings and Magnsdottir 2014; Deser et al. 2016; Blackport and Kushner 2017; Zappa et al. 2018). On the other hand, the uncertainty in future projections of tropical Pacific SST may affect the midlatitude teleconnections, through exciting the Pacific-North America pattern. This influence is strongly linked to the uncertainty in future projections of the jet streams over the North Pacific and the North Atlantic (Delcambre et al. 2013), the North Atlantic storm tracks (Ciasto et al. 2016), and the northern annual mode (Cattiaux and Cassou 2013).

Based on the aforementioned studies, we hypothesize that the uncertainty in future projections of SST and SIC could cause significant uncertainty in the response of the Northern Hemisphere atmospheric circulation. Although previous studies have analyzed the relative contribution of SST and SIC to this uncertainty, few studies have used more than one model to assess the robustness of the linkages between future projections of SST/SIC and atmospheric circulation across 
(a) Multi-model mean response

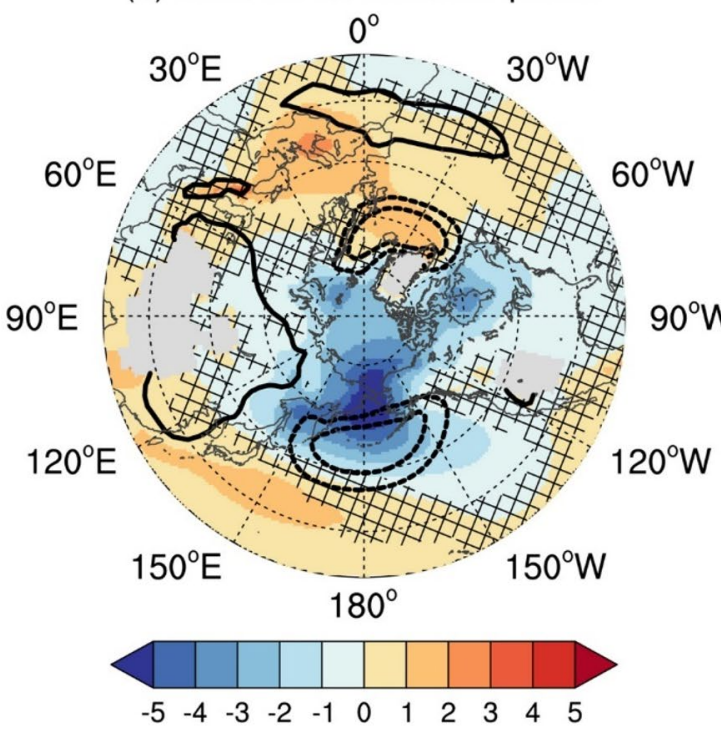

Fig. 1 Multi-model mean (MME) of the DJF sea level pressure (SLP) in 1971/72-2000/01 of the historical run (thick contours: solid lines indicate $1023 \mathrm{hPa}$ and dashed lines indicate 1002 and $1006 \mathrm{hPa}$ ), and the forced response (shading) based on ten CMIP5 models listed in Table 1: (a) the MME forced response, where cross-hatch indicates the regions that less than eight models agree on the sign of MME change, (b) the uncertainty in the forced response (inter-model stand-

climate models and to understand the underlying mechanisms. To address this issue, we perform experiments with two atmosphere-only general circulation models (AGCMs) using the monthly-varying SST and SIC patterns that are related to the uncertainty in future projections of the SLP. From these experiments we will deduce if future climate projections of the SLP could be constrained by improving the simulations of specific SST and SIC patterns. Specifically, we address the following questions:

1) What are the large-scale spatial patterns representing the uncertainty in future projections of the Northern Hemisphere SLP? What are the corresponding SST and SIC patterns?

2) To what extent do AGCMs reproduce these SLP patterns when forced by these corresponding SST and SIC patterns? Do the mechanisms simulated by the AGCMs correspond to those of the CMIP5 inter-model differences, estimated from ten models with at least three ensemble members?

We focus on the winter (DJF) climate projections from the CMIP5 RCP8.5 scenario, which is the highest emission scenario and thus produces the strongest externally forced responses. The projected climate change is considered for the late twenty-first century (2069-2098) relative to the (b) Model response uncertainty

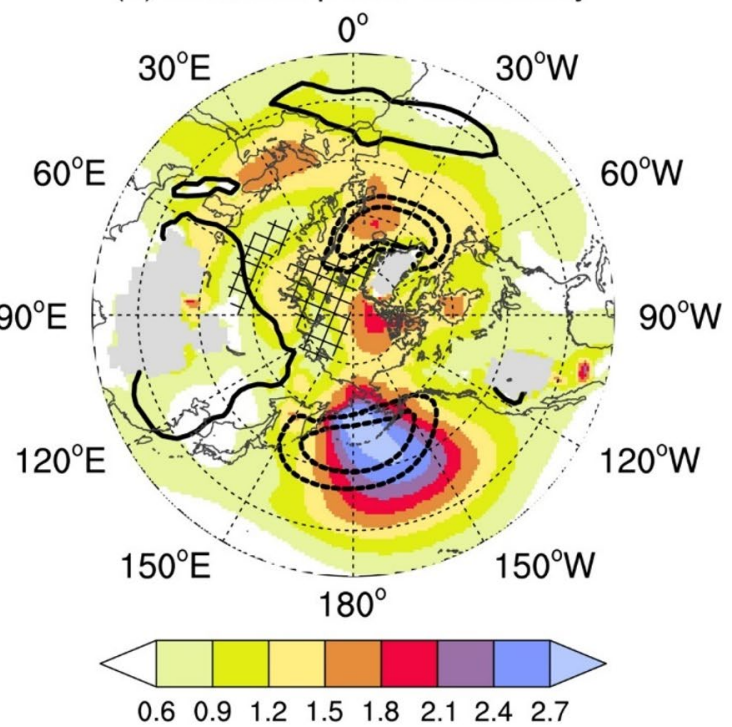

ard deviation of the projection), where cross-hatch indicates the regions that the uncertainty is not significantly larger than the internal climate variability (intra-model standard deviation of the projection) at the $90 \%$ confidence level of $F$-test. Unit: hPa. The outermost latitude circle is $20^{\circ} \mathrm{N}$, and other latitude circles represent $30^{\circ} \mathrm{N}$ to $75^{\circ} \mathrm{N}$ with a spacing of $15^{\circ}$

late twentieth century (1971-2000), which is referred to as "response" hereafter. For example, the projected change of SLP is called the SLP response.

To identify uncertainties that are inherent to individual models requires large-ensemble simulations (Deser et al. 2020). The requirement is especially true for the winter extratropical circulation where large internal climate variability can even mask the signals from strong external forcing (Deser et al. 2012). Thus, we analyze simulations from ten CMIP5 coupled models that have at least three ensemble members in the historical and RCP8.5 runs (Table 1); this is to try to minimally limit noise from internal variability. This selection was limited by the availability of model simulations at the time this study was started (CSIRO-Mk-3.6.0 was also available, but is not included because its SST and SIC biases were too large). We average across ensemble members of each model to increase the signal-to-noise ratio for the external forcing, where the response averaged across the ensemble members is called the "forced response". The MME forced response is the unweighted average of the forced response from the ten CMIP5 models.

In the following, Sect. 2 analyzes the uncertainty in the forced response of DJF SLP from the ten CMIP5 models. Section 3 summarizes our modelling approach and describes the design of sensitivity experiments and diagnostics. Section 4 compares simulated responses from the sensitivity 
Table 1 List of CMIP5 coupled models

\begin{tabular}{lllll}
\hline Number & Model & $\begin{array}{l}\text { Ensemble mem- } \\
\text { bers (r\{n\}i1p1) }\end{array}$ & $\begin{array}{l}\text { Horizontal resolution of } \\
\text { atmospheric model (lat } \times \text { lon) }\end{array}$ & $\begin{array}{l}\text { Horizontal resolu- } \\
\text { tion of ocean model } \\
\text { (lat } \times \text { lon) }\end{array}$ \\
\hline 1 & CanESM2 & $1-5$ & $2.8^{\circ} \times 2.8^{\circ}$ & $0.9^{\circ} \times 1.4^{\circ}$ \\
2 & CCSM4 & $1-6$ & $0.9^{\circ} \times 1.3^{\circ}$ & $0.6^{\circ} \times 0.9^{\circ}$ \\
3 & CESM1-CAM5 & $1-3$ & $0.9^{\circ} \times 1.3^{\circ}$ & $0.6^{\circ} \times 0.9^{\circ}$ \\
4 & CNRM-CM5 & $1,2,4,6,10$ & $1.4^{\circ} \times 1.4^{\circ}$ & $0.6^{\circ} \times 1.0^{\circ}$ \\
5 & FIO-ESM & $1-3$ & $2.8^{\circ} \times 2.8^{\circ}$ & $0.5^{\circ} \times 1.1^{\circ}$ \\
6 & HadGEM2-CC & $1-3$ & $1.3^{\circ} \times 1.9^{\circ}$ & $0.8^{\circ} \times 1.0^{\circ}$ \\
7 & HadGEM2-ES & $1-4$ & $1.3^{\circ} \times 1.9^{\circ}$ & $0.8^{\circ} \times 1.0^{\circ}$ \\
8 & IPSL-CM5A-LR & $1-4$ & $1.9^{\circ} \times 3.8^{\circ}$ & $1.2^{\circ} \times 2.0^{\circ}$ \\
9 & MIROC5 & $1-3$ & $1.4^{\circ} \times 1.4^{\circ}$ & $0.8^{\circ} \times 1.4^{\circ}$ \\
10 & MPI-ESM-LR & $1-3$ & $1.9^{\circ} \times 1.9^{\circ}$ & $0.8^{\circ} \times 1.4^{\circ}$ \\
\hline
\end{tabular}

experiments to the uncertainty in forced responses of the ten CMIP5 models, and analyzes the possible dynamics. Section 5 provides a discussion and conclusion.

\section{Uncertainty in the forced response of DJF SLP}

The ten CMIP5 models consistently indicate that global warming will cause SLP to decrease in the high-latitudes over the Arctic, Northeast America, and North Pacific (Fig. 1a). Concomitantly, SLP increases over the midlatitude North Atlantic near the Icelandic low and the Mediterranean (Fig. 1a). These results are generally consistent with Collins et al. (2013; their Fig. 12.18), except that weakening of the Icelandic low is more substantial in the ten CMIP5 models. In contrast, these models do not agree well on the forced SLP response in the subtropical region $\left(\sim 30^{\circ}-40^{\circ} \mathrm{N}\right)$, including the Azores high, the eastern North Pacific, the Middle East and the East Asian continent (i.e., as there is little agreement on sign of the response, as indicated by stippling). The agreement is also small in the northeastern flank of the Icelandic low and Scandinavia, as well as the southern part of the Aleutian low.

The uncertainty in the forced SLP response is quantified by the inter-model standard deviation (computed from the individual model ensemble means; Fig. 1b). The uncertainty is largest near the center of Aleutian low, and is large over the Canadian Archipelago and the northeastern Atlantic (east of the Icelandic low). Compared to the uncertainty in the forced SLP response (Fig. 1b), the internal climate variability in the SLP response is significantly higher over the Eurasian side of the Arctic, and it is comparable over the northeastern Atlantic and the high-latitude Eurasia (Fig. S1a). This highlights the importance of, where possible, using more than three ensemble members to reduce the internal climate variability.
The internal climate variability in the ensemble mean is reduced by one over the square root of the ensemble size, and for the three members is $\sim 0.6$. Thus, the selected ten CMIP5 models appear to largely capture the uncertainty and internal variability in the response across the 34 available CMIP5 models: the uncertainty pattern computed from all ensemble members of the ten CMIP5 models is very similar to that computed from single ensemble members of the 34 available CMIP5 models (pattern correlation of +0.94 ), with only slightly lower amplitude (Fig. S1b, c). However, as the 34 models have mostly only one ensemble member, they may not provide a good estimate of the forced response uncertainty, which can be smaller than the internal variability over the high latitudes (i.e., Fig. S1a vs. Figure 1b). Hence, in the following our analysis is confined to the ten CMIP5 models.

The dominant modes of the uncertainty in the forced SLP response are identified by performing an inter-model empirical orthogonal function (EOF) analysis on the forced response in DJF SLP from the ten CMIP5 models over the domain $20^{\circ}-90^{\circ} \mathrm{N}$ (Fig. 2). In the EOF analysis, the MME forced response is removed prior to computing the covariance matrix, which is weighted by the square root of the cosine of latitude to account for the change in grid size. As shown in Fig. 2a, the first mode (EOF1) has the strongest positive loading over the North Pacific and mainly characterizes weakening or strengthening of the Aleutian low, a positive loading over the northeastern Atlantic and a negative loading near the Mediterranean. The second mode (EOF2) has a strong positive loading over the southeastern flank of the Icelandic low and a strong negative loading over the Hudson Bay $\left(60^{\circ} \mathrm{N}, 90^{\circ} \mathrm{W}\right.$; Fig. 2b). The spatial pattern of EOF2 over the North Pacific represents a shift in the Aleutian low, with a positive loading in its eastern flank and a negative loading in its northwestern flank. Overall, EOF1 and EOF2 separately capture the two major centers in the uncertainty in the forced SLP response (Fig. 1b). 


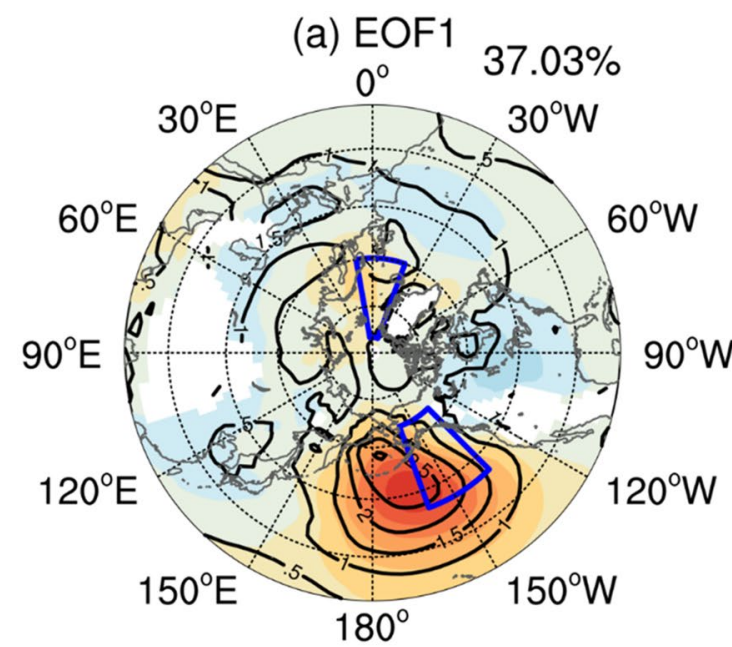

(c) $\mathrm{PA}_{\triangle \mathrm{SLP}}(\mathrm{EOF} 1+\mathrm{EOF} 2)$
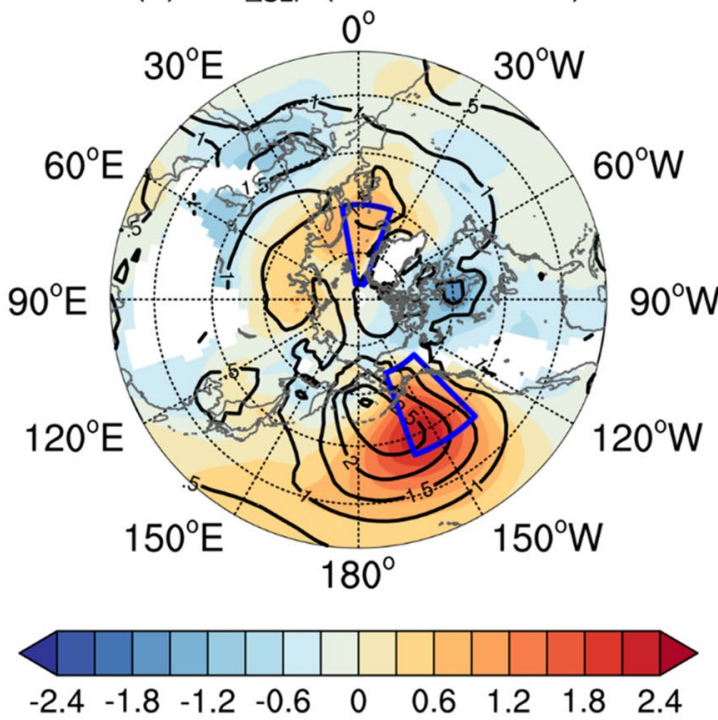

Fig. 2 a-b First two eigenvectors (EOF1 and EOF2; shading) and the uncertainty (inter-model standard deviation; contour) in the forced DJF SLP response of the ten CMIP5 models, (c) As in (a)-(b), but for the sum of EOF1 and EOF2, which is called the Pacific-Atlantic SLP uncertainty pattern $\left(\mathrm{PA}_{\Delta \mathrm{SLP}}\right),(\mathbf{d})$ the inter-model relationship

Previous studies have investigated the uncertainty in circulation responses over the North Pacific (e.g., Gan et al. 2017) and the North Atlantic (e.g., Harvey et al. 2015) separately. However, the uncertainty in the forced SLP response over the northeastern Pacific $\left(40^{\circ}-65^{\circ} \mathrm{N}\right.$ and $\left.160^{\circ}-135^{\circ} \mathrm{W}\right)$ and over the northeastern Atlantic $\left(60^{\circ}-85^{\circ} \mathrm{N}\right.$ and $\left.20^{\circ} \mathrm{W}-10^{\circ} \mathrm{E}\right)$ is strongly correlated $(+0.770, p<0.05$, Fig. 2d). These uncertainties are partly captured by EOF1 and EOF2, which are not well separated according to the North's rule of thumb (North et al. 1982). In other words, the EOF analysis is not able to isolate the coherence of the SLP response over the Pacific and the Atlantic in the ten CMIP5

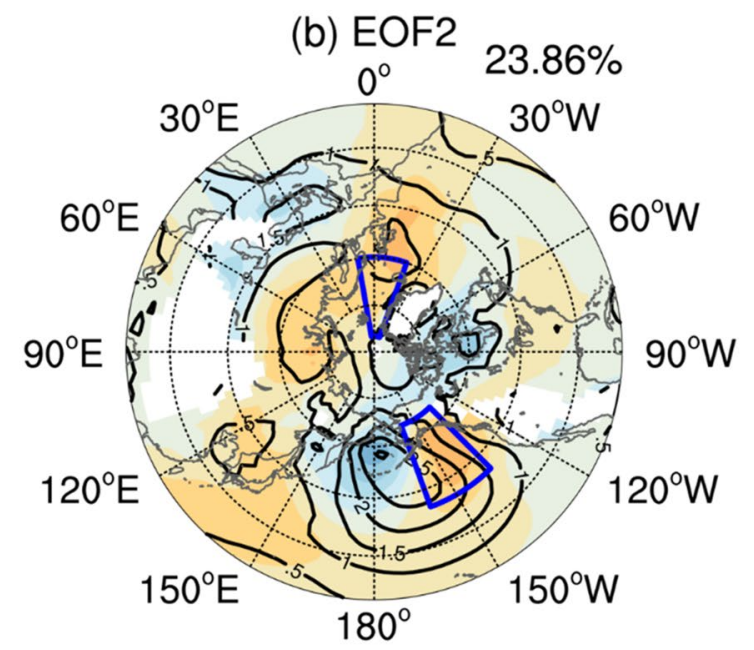

(d) regional SLP

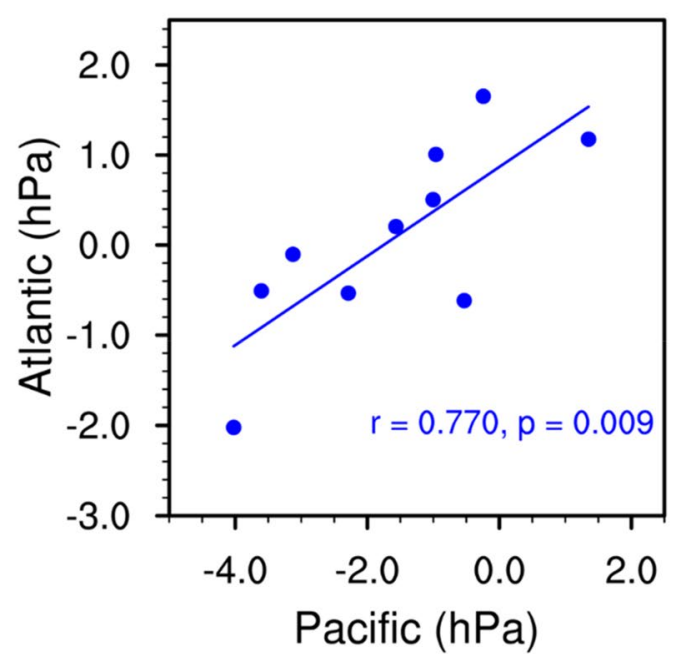

between the forced SLP response over the northeastern Atlantic $\left(60^{\circ}-\right.$ $85^{\circ} \mathrm{N}$ and $\left.20^{\circ} \mathrm{W}-10^{\circ} \mathrm{E}\right)$ and over the northeastern Pacific $\left(40^{\circ}-65^{\circ} \mathrm{N}\right.$ and $\left.160^{\circ}-135^{\circ} \mathrm{W}\right)$, where these regions are represented by the blue boxes in (a)-(c). Unit: hPa. The outermost latitude circle is $20^{\circ} \mathrm{N}$, and other latitude circles represent $30^{\circ} \mathrm{N}$ to $75^{\circ} \mathrm{N}$ with a spacing of $15^{\circ}$

models. Thus, we adopt a simple approach to adequately represent this coherence: we add EOF1 and EOF2 to form a Pacific-Atlantic SLP uncertainty pattern $\left(\mathrm{PA}_{\Delta \mathrm{SLP}}\right)^{1}$ that captures both uncertainties (Fig. 2c) and accounts for $31 \%$ of the total variance. The forced SLP response in the ten CMIP5 models is projected onto the $\mathrm{PA}_{\Delta \mathrm{SLP}}$ pattern to get an

\footnotetext{
1 This operation describes a 45-degree rotation in EOF1-EOF2 space. We add EOF1 and EOF2 because (i) the SLP uncertainty over the northeastern Pacific and over the northeastern Atlantic is significantly positively correlated, and (ii) in both EOF1 and EOF2 these two regions are of the same sign.
} 
Fig. 3 Flow chart summarizing the three-tiered approach in this study

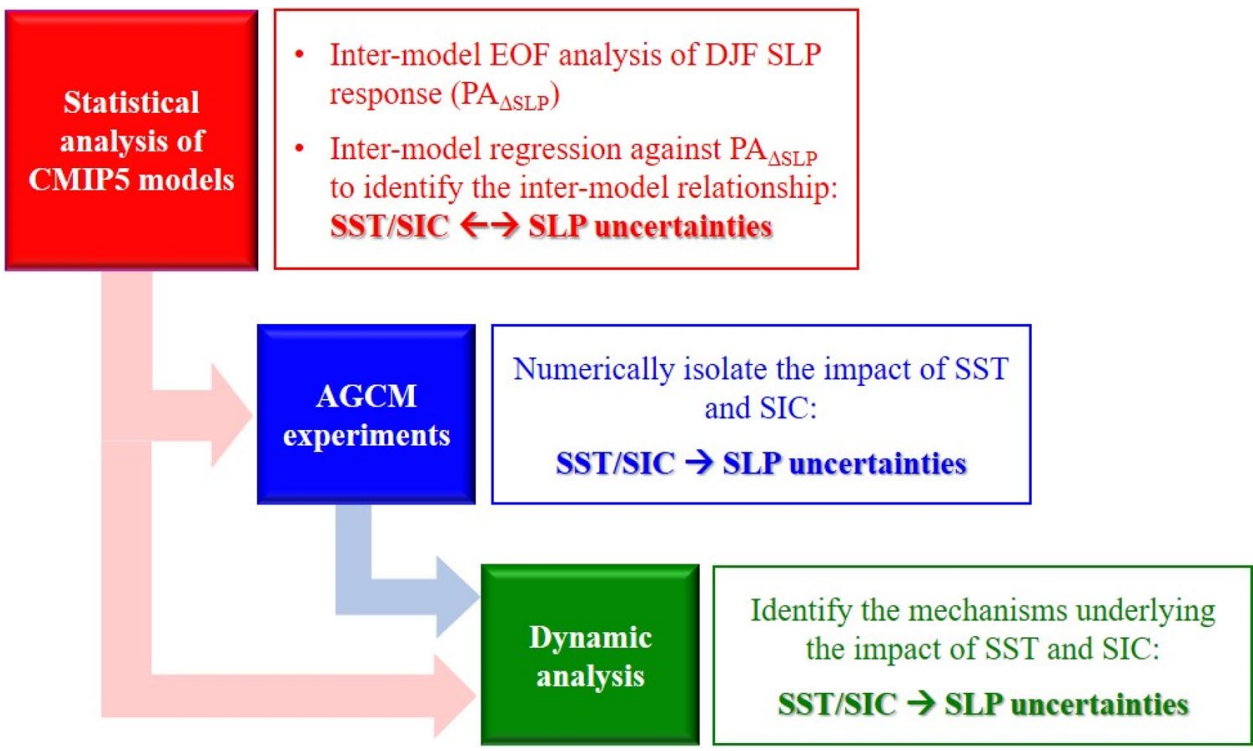

Table 2 Terminology in this study

\begin{tabular}{|c|c|}
\hline Term & Meaning \\
\hline Winter & $\begin{array}{l}\text { December-January-Febraury (DJF). For example, the winter } 2000 \text { refers to the period between December } 2000 \text { and } \\
\text { February } 2001\end{array}$ \\
\hline Internal climate variability & $\begin{array}{l}\text { Intra-model standard deviation, where the standard deviation computed from the individual ensemble members } \\
\text { removing the ensemble mean of each CMIP5 model }\end{array}$ \\
\hline Response & $\begin{array}{l}\text { For CMIP5 models: climate projection based on the difference between the winter } 2069 \text { to } 2098 \text { in the RCP8.5 run } \\
\text { and the winter } 1971 \text { to } 2000 \text { in the historical run } \\
\text { For AGCMs: Difference between one set of two perturbation runs listed in Table } 3\end{array}$ \\
\hline Forced response & Average of response across all ensemble members of individual CMIP5 models \\
\hline Uncertainty & The inter-model spread across CMIP5 models \\
\hline $\mathrm{PA}_{\Delta \mathrm{SLP}}$ & $\begin{array}{l}\text { The Pacific-Atlantic SLP uncertainty pattern, which is the sum of EOF1 and EOF2 derived from the inter-model } \\
\text { EOF analysis of the DJF SLP response in ten CMIP5 models }\end{array}$ \\
\hline $\mathrm{PAI}_{\Delta \mathrm{SLP}}$ & The principal component of PA $\mathrm{SSLP}_{\text {in }}$ the ten CMIP5 models \\
\hline [] $]_{\Delta \mathrm{SLP}}$ & The variable linearly regressed against $\mathrm{PAI}_{\Delta \mathrm{SLP}}$ \\
\hline
\end{tabular}

index $\left(\mathrm{PAI}_{\triangle \mathrm{SLP}}=\mathrm{PC} 1+\mathrm{PC} 2\right)$ for the SLP uncertainty among the models.

\section{Methods}

\subsection{Approach}

We use two AGCMs in order to understand the impact of SST and Arctic sea ice on the uncertainty in the forced SLP response. The approach of this study is outlined in Fig. 3, and terminologies referring to CMIP5 models and AGCM simulations are listed in Table 2. The approach assumes that AGCM experiments with prescribed SST/SIC can be used to understand uncertainties in atmospheric circulation identified from CMIP5. This approach has been proven useful for understanding the impact of SST/SIC on atmospheric circulation when the atmospheric component of a coupled model is driven with surface boundary conditions from the same coupled model (Chen et al. 2013; Colfescu et al. 2013; Omrani et al. 2016; Colfescu and Schneider, 2017). A similar study to ours has used a single AGCM to understand uncertainties in MME (Harvey et al. 2015).

If the experiments in both AGCMs reproduce the forced uncertainty from the ten CMIP5 models, our results would indicate that improving the simulation of SST/SIC could reduce the uncertainties in climate change. However, the two AGCMs may not fully reproduce the uncertainty pattern, or the AGCMs may even disagree with each other. Then, the uncertainties could be related to the atmospheric component, but also potentially to the misrepresentation of air-sea interactions in AGCM experiments. We expect the actual outcomes will vary with location. 


\subsection{Models}

The first AGCM is version 4.0 of the Community Atmosphere Model (CAM4) developed by the National Center for Atmospheric Research (NCAR) with a horizontal resolution of $0.9^{\circ} \times 1.25^{\circ}(\sim 100 \mathrm{~km})$ and 26 vertical levels up to $3 \mathrm{hPa}$ (Neale et al. 2013). The second AGCM is the atmospheric component of the EC-Earth 3.1 model (Döscher et al. 2021), which is based on the Integrated Forecast System (IFS) cycle 36r4 developed by the European Centre for Medium-Range Weather Forecasts (ECMWF). Here, IFS is used in T255 horizontal resolution $(\sim 80 \mathrm{~km})$ with 91 vertical levels up to $0.01 \mathrm{hPa}$ (Balsamo et al. 2009).

\subsection{Design of experiments}

\subsubsection{Prescribed SST and SIC patterns}

In the experiments, we prescribe SST and SIC patterns $\left(\mathrm{SST}_{\Delta \mathrm{SLP}}\right.$ and $\left.\mathrm{SIC}_{\Delta \mathrm{SLP}}\right)$ that are computed by linear regression of the forced response in SST and SIC against PAI ${ }_{\triangle S L P}$ across the ten CMIP5 models. The patterns are computed for each calendar month and have an amplitude corresponding to one unit of the standardized index. To attribute a physical meaning of SST and SIC patterns, we illustrate the intermodel regression patterns of DJF SST and SIC, which are referred to as the DJF $\operatorname{SST}_{\triangle \mathrm{SLP}}$ and $\mathrm{SIC}_{\triangle \mathrm{SLP}}$ (Fig. 4a-b). Note that $\mathrm{SST}_{\Delta S L P}$ is global and $\mathrm{SIC}_{\Delta \mathrm{SLP}}$ is restricted to the Northern Hemisphere, but SST changes consistently with SIC (see the last paragraph in Sect. 3.3.2 and Table 3 for details).

The uncertainty in the forced SST response is generally larger at high latitudes (Fig. 4a). In the Northern Hemisphere, it is especially large over the Barents-Kara Sea and the midlatitude North Atlantic. The DJF SST ${ }_{\triangle S L P}$ (associated with positive $\mathrm{PAI}_{\triangle \mathrm{SLP}}$ ) captures these SST uncertainties, representing a substantial weakening in the SST gradient between the tropics and the northern high-latitudes compared to the MME forced response (Fig. 4c). SST $_{\Delta S L P}$ also represents a warmer Northern Hemisphere and a cooler Southern Hemisphere than the MME forced response, suggesting that $\mathrm{PA}_{\triangle \mathrm{SLP}}$ also co-varies with a reduced inter-hemispheric SST gradient. Moreover, $\mathrm{SST}_{\triangle \mathrm{SLP}}$ is associated with weakening in the zonal SST gradient between the equatorial western and eastern Pacific, where the climatological mean SST is higher in the western Pacific (warm-pool region).

The uncertainty in the forced response of the Arctic SIC is largest in the Kara Sea $\left(\sim 60^{\circ}-90^{\circ} \mathrm{E}\right)$ and has a secondary maximum north of the Laptev Sea $\left(\sim 120^{\circ} \mathrm{E}\right)$ (Fig. $\left.4 \mathrm{~b}\right)$. The

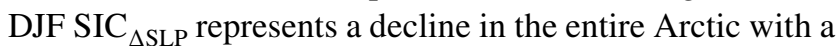
larger decline in these two seas. Therefore, $\mathrm{PA}_{\Delta \mathrm{SLP}}$ co-varies with the total Arctic sea ice extent (Fig. 4f) in a consistent manner with the high-latitude SST (Fig. 4a).

\subsection{2 "Time-slice" sensitivity experiments}

We conducted three sets of AGCM "time-slice" sensitivity experiments forced by monthly-varying SST and SIC repeated for 60 annual cycles in CAM4 and 50 annual cycles in IFS (Table 3), such that the mean response in each model increases the signal-to-noise ratio. The prescribed SST and SIC are based on the 2069-2098 monthly climatology in the CMIP5 RCP8.5 scenario ( $\mathrm{SST}_{\mathrm{MME}}$ and $\mathrm{SIC}_{\mathrm{MME}}$ ) and the monthly-varying $\mathrm{SST}_{\Delta S L P}$ and $\mathrm{SIC}_{\Delta \mathrm{SLP}}$ (Figs. S2 and $\mathrm{S} 3$ ). Consistently, the prescribed radiative forcing (greenhouse gas concentrations and aerosol concentrations) are the 2069-2098 monthly climatology from the CMIP5 RCP8.5 scenario.

The boundary conditions of SST and SIC in any set of sensitivity experiments were prepared by adding or subtracting half the monthly-varying $\mathrm{SST}_{\Delta \mathrm{SLP}}$ and $\mathrm{SIC}_{\Delta \mathrm{SLP}}$. The difference between the boundary conditions of two runs in one set of experiments is equivalent to one unit of the intermodel regression patterns of SST and SIC. Thus, the magnitude of atmospheric response can be directly compared to that of the inter-model regression pattern from the ten CMIP5 models.

In the first set of experiments (run1 and run2), both SST and SIC were modified and they are called SST + SIC perturbation runs. In run1, half the monthly-varying $\mathrm{SST}_{\triangle \mathrm{SLP}}$ and SIC $_{\triangle \text { SLP }}$ were added to the 2069-2098 monthly climatology of SST and SIC respectively ( $\mathrm{SST}_{\mathrm{MME}}$ and $\mathrm{SIC}_{\mathrm{MME}}$ ) to form the boundary conditions. Conversely, in run2, half the monthlyvarying $\mathrm{SST}_{\triangle \mathrm{SLP}}$ and $\mathrm{SIC}_{\Delta \mathrm{SLP}}$ were subtracted from $\mathrm{SST}_{\mathrm{MME}}$ and SIC $_{\mathrm{MME}}$ to form the boundary conditions. It is assumed that SST and SIC change coherently as the inter-model regression analysis (Figs. S2 and S3), so we did not perform experiments with the boundary conditions $\mathrm{SST}_{\mathrm{MME}}+\mathrm{SST}_{\Delta \mathrm{SLP}}$ with $\mathrm{SIC}_{\mathrm{MME}}-\mathrm{SIC}_{\triangle \mathrm{SLP}}$, and $\mathrm{SST}_{\mathrm{MME}}-\mathrm{SST}_{\Delta \mathrm{SLP}}$ with $\mathrm{SIC}_{\mathrm{MME}}+\mathrm{SIC}_{\Delta \mathrm{SLP}}$. In the second set of experiments (run3 and run4), SST was changed as in run1 and run2 while SIC was the $\mathrm{SIC}_{\mathrm{MME}}$; they are called SST perturbation runs. Finally, in the third set of experiments (run5 and run6), SIC was changed as in run1 and run2 while SST was the $\mathrm{SST}_{\mathrm{MME}}$; they are called SIC perturbation runs.

We follow Screen et al. (2013)'s approach to ensure that SST and SIC are consistent with each other. In the Northern Hemisphere, for grid cells with sizeable SIC perturbation $\left(\mathrm{ISIC}_{\Delta \mathrm{SLP}} \mid\right.$ $\geq+0.1$ (fraction)), the boundary condition of SST was modified to $\mathrm{SST}_{\mathrm{MME}}$ in the SST perturbation runs (run3 and run4) and to $\mathrm{SST}_{\mathrm{MME}} \pm 0.5 \times \mathrm{SST}_{\Delta \mathrm{SLP}}$ in the SIC perturbation runs (run5 and run6). In the Southern Hemisphere (where SIC $_{\Delta \mathrm{SLP}}$ 
(a) sea surface temperature (SST)

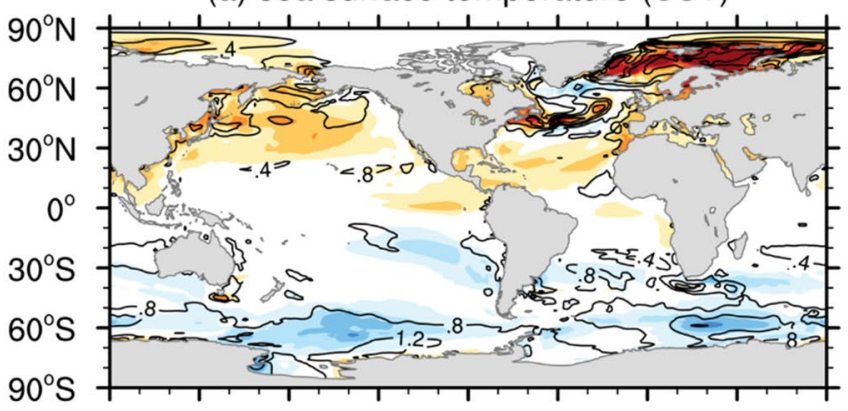

$90^{\circ} \mathrm{E} 135^{\circ} \mathrm{E} 180^{\circ} 135^{\circ} \mathrm{W} 90^{\circ} \mathrm{W} 45^{\circ} \mathrm{W} \quad 0^{\circ} \quad 45^{\circ} \mathrm{E} \quad 90^{\circ} \mathrm{E}$

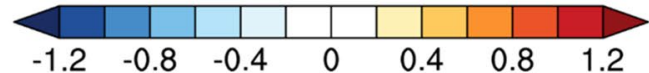

(c) SST $\left(30^{\circ} \mathrm{S}-30^{\circ} \mathrm{N}\right.$ minus $\left.30^{\circ}-90^{\circ} \mathrm{N}\right)$

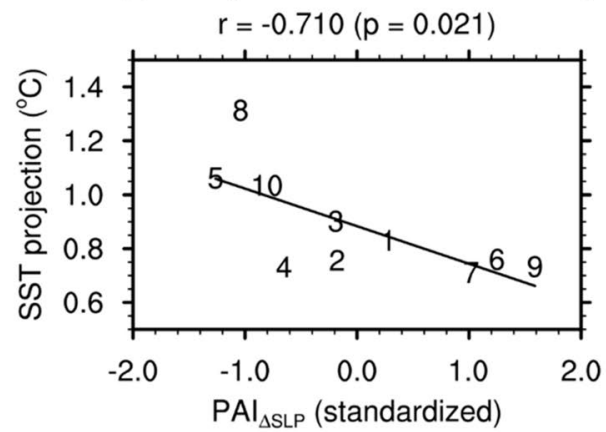

(e) Zonal SST gradient $\left(135^{\circ} \mathrm{E}-180^{\circ}\right.$ minus $135^{\circ}-90^{\circ} \mathrm{W}$ at $5^{\circ} \mathrm{S}-5^{\circ} \mathrm{N}$

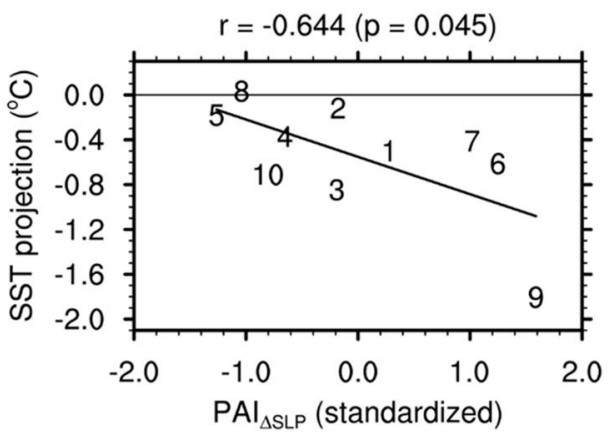

(b) Arctic sea ice concentrations (SIC)

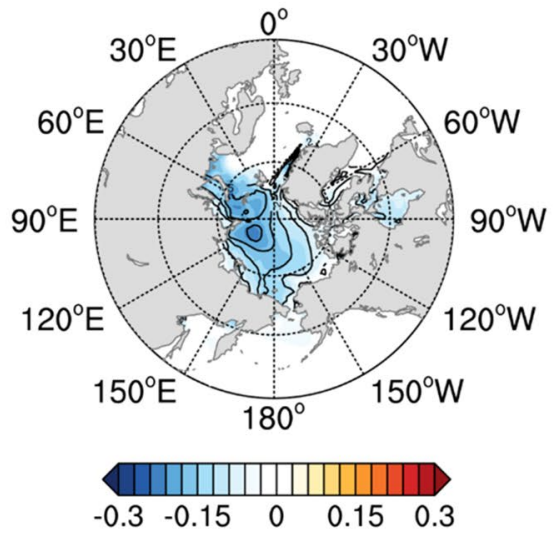

(d) SST $\left(90^{\circ} \mathrm{S}-0^{\circ}\right.$ minus $\left.0^{\circ}-90^{\circ} \mathrm{N}\right)$

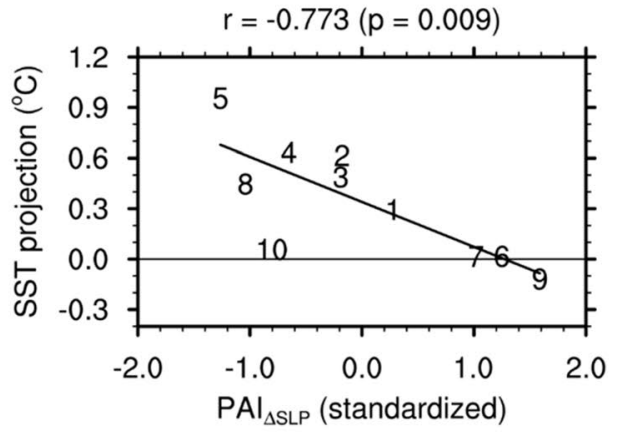

(f) Total Arctic sea ice extent (SIE)

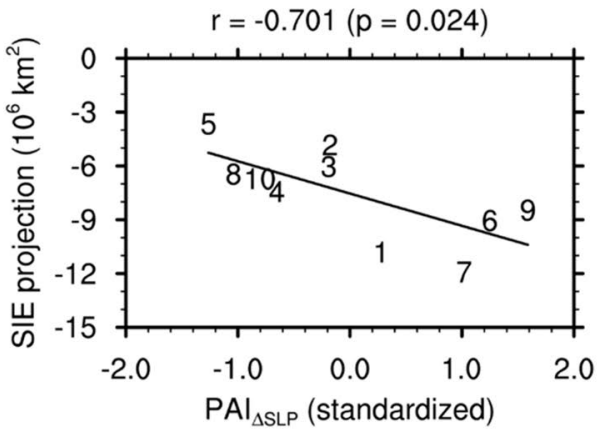

Fig. 4 a-b Inter-model regression of the forced response against $\mathrm{PAI}_{\triangle \mathrm{SLP}}$ (shading) and the uncertainty in the forced response (i.e., inter-model standard deviation; contour) of the ten CMIP5 models: (a) SST (contour interval: $0.4{ }^{\circ} \mathrm{C}$ ), (b) SIC (contour interval: 0.1 fraction), where the outermost circle in the polar stereographic map

is zero), for grid cells with SIC $\geq 0.1$ (fraction), the boundary condition of SST was modified to $\mathrm{SST}_{\mathrm{MME}}$ in all runs. Otherwise the boundary condition of SST was set as in Table 3. The monthly-varying SIC boundary condition of run 1 and run 5 (larger SIC and SST response) and the monthly-varying SIC boundary condition of run 2 and run 6 (smaller SIC and SST response) are shown in Fig. S4 and Fig. S5, respectively. is $45^{\circ} \mathrm{N}$. c-e Scatterplot of the inter-model relationship between $\mathrm{PAI}_{\triangle \mathrm{SLP}}$ (abscissa) and the future projection (ordinate): (c) the equator-to-pole SST gradient, (d) the inter-hemispheric SST gradient, (e) the zonal SST gradient between the equatorial western and eastern Pacific $\left({ }^{\circ} \mathrm{C}\right)$, and (f) the total Arctic sea ice extent $\left(10^{6} \mathrm{~km}^{2}\right)$

\subsection{Diagnostics}

Given that the SST perturbation represents a weaker meridional SST gradient between the low and high latitudes and the SIC perturbation represents a stronger decline of panArctic SIC, the perturbations may trigger responses in the zonal-mean mass-stream function. Moreover, tropical SST 
Table 3 List of AGCM sensitivity experiments, where the subscript MME and $\triangle \mathrm{SLP}$ denotes the MME in 2069-2098 and the inter-model regression pattern

\begin{tabular}{llll}
\hline Type & Run & Prescribed monthly-varying SST & Prescribed monthly-varying SIC \\
\hline SST + SIC perturbation runs & 1 & $\mathrm{SST}_{\mathrm{MME}}+0.5 \times \mathrm{SST}_{\Delta \mathrm{SLP}}$ & $\mathrm{SIC}_{\mathrm{MME}}+0.5 \times \mathrm{SIC}_{\Delta \mathrm{SLP}}$ \\
& 2 & $\mathrm{SST}_{\mathrm{MME}}-0.5 \times \mathrm{SST}_{\Delta \mathrm{SLP}}$ & $\mathrm{SIC}_{\mathrm{MME}}-0.5 \times \mathrm{SIC}_{\Delta \mathrm{SLP}}$ \\
\multirow{2}{*}{ SST perturbation runs } & 3 & $\mathrm{SST}_{\mathrm{MME}}+0.5 \times \mathrm{SST}_{\Delta \mathrm{SLP}} *$ & $\mathrm{SIC}_{\mathrm{MME}}$ \\
& 4 & $\mathrm{SST}_{\mathrm{MME}}-0.5 \times \mathrm{SST}_{\Delta \mathrm{SLP}} *$ & $\mathrm{SIC}_{\mathrm{MME}}$ \\
SIC perturbation runs & 5 & $\mathrm{SST}_{\mathrm{MME}} *$ & $\mathrm{SIC}_{\mathrm{MME}}+0.5 \times \mathrm{SIC}_{\Delta \mathrm{SLP}}$ \\
& 6 & $\mathrm{SST}_{\mathrm{MME}} *$ & $\mathrm{SIC}_{\mathrm{MME}}-0.5 \times \mathrm{SIC}_{\Delta \mathrm{SLP}}$ \\
\hline
\end{tabular}

*For grids in the Northern Hemisphere with $\left|\mathrm{SIC}_{\Delta \mathrm{SLP}}\right| \geq 0.1$ (fraction), $\mathrm{SST}_{\Delta \mathrm{SLP}}$ changes consistently with SIC (see text for details). Note that $\mathrm{SST}_{\triangle \mathrm{SLP}}$ also changes consistently with SIC in the Southern Hemisphere, where SST is set as $\mathrm{SST}_{\mathrm{MME}}$ for the grids with $\mathrm{SIC}_{\mathrm{MME}} \geq 0.1$ (fraction) perturbations may excite circulation through a midlatitude Rossby wavetrain (teleconnection) (Horel and Wallace 1981; Ding et al. 2014; England et al. 2020). To link the tropical circulation to the midlatitude atmospheric circulation, we will present responses in the divergent wind $\boldsymbol{V}_{\chi}$, the velocity potential $\left(\chi=\nabla^{-2}(\nabla \cdot V)\right)$ and the Rossby wave source $(S)$, where the Rossby wave source is defined as in Sardeshmukh and Hoskins (1988):

$$
S^{\prime}=\underbrace{-\bar{\zeta} \nabla \cdot V^{\prime} \chi-\zeta \prime \nabla \cdot \bar{V}_{\chi}}_{\text {stretching }} \underbrace{-\bar{V}_{\chi} \cdot \nabla \zeta^{\prime}-V^{\prime} \chi \cdot \nabla \bar{\zeta}}_{\text {advection }}
$$

where $\zeta$ is the absolute vorticity. The overbar denotes the basic state and the prime denotes the inter-model regression of the forced response against $\mathrm{PAI}_{\Delta \mathrm{SLP}}$ across the ten CMIP5 models or the response in the AGCM sensitivity experiments. On the R.H.S. of (1), the first two terms are the contribution from the vortex stretching, where in the first (second) term a stronger convergence of the wind response (climatology) would enhance the cyclonic Rossby wave source. In contrast, stronger divergence would enhance the anticyclonic Rossby wave source. The third and fourth terms are the contribution from the vorticity advection by the divergent wind, where the region with a strong vorticity gradient would enhance or reduce the Rossby wave source. When the response of the Rossby wave source is compared to the pressure response, we could deduce if the tropical-midlatitude interaction is crucial for the pressure response.

To further demonstrate if the midlatitude atmospheric response is a Rossby wave train, we will present the horizontal component of stationary wave activity fluxes at the 250-hPa (Takaya and Nakamura 2001): where $U$ and $V$ are the zonal and meridional component of the basic flow $\boldsymbol{V}, p$ is the pressure level, $\psi^{\prime}$ is the intermodel regression of the forced response against $\mathrm{PAI}_{\Delta \mathrm{SLP}}$ across the ten CMIP5 models or the streamfunction response in the AGCM sensitivity experiments. Because the direction of wave activity fluxes is parallel to the group velocity, this diagnostic identifies the response in Rossby wave propagation.

\section{Results}

\subsection{Mechanisms underlying the CMIP5 SLP uncertainty pattern}

We now identify the potential mechanisms explaining the relation between the SLP uncertainty pattern $\left(\mathrm{PA}_{\Delta \mathrm{SLP}}\right)$ and the SST and SIC uncertainty patterns in the ten CMIP5 models (analysis shown in Figs. 5a-b, 6a and 7a-c; other panels in Figs. 5 and 6 will be discussed in subsequent sections in order to compare the results from sensitivity experiments to the CMIP5 models). The regression of $\mathrm{PAI}_{\triangle \mathrm{SLP}}$ against the forced DJF SLP response reveals increasing SLP in the northeastern Pacific and the northeastern Atlantic (Fig. 5a). These positive SLP regions coincide with positive $250-\mathrm{hPa}$ height regions (Fig. 5b), suggesting an equivalent barotropic structure. Moreover, positive $\mathrm{PAI}_{\Delta \mathrm{SLP}}$ is associated with increasing SLP over the tropical Indo-Pacific and decreasing SLP in most of the polar region, including the Arctic and Northeast America with a maximum around the Canadian Archipelago (Fig. 5a). It is also associated with a dipole pattern centered over Europe, with increasing SLP near the latitude of the Icelandic low and decreasing SLP in the Mediterranean and the Middle East (Fig. 5a). We will investigate how these SLP uncertainties are

$\boldsymbol{W}=\frac{p \cos \phi}{2|V|}\left\{\begin{array}{c}\frac{U}{a^{2} \cos ^{2} \phi}\left[\left(\frac{\partial \psi^{\prime}}{\partial \lambda}\right)^{2}-\psi^{\prime} \frac{\partial^{2} \psi^{\prime}}{\partial \lambda^{2}}\right]+\frac{V}{a^{2} \cos \phi}\left(\frac{\partial \psi^{\prime}}{\partial \lambda} \frac{\partial \psi^{\prime}}{\partial \phi}-\psi^{\prime} \frac{\partial^{2} \psi^{\prime}}{\partial \lambda \partial \phi}\right) \\ \frac{U}{a^{2} \cos ^{2} \phi}\left(\frac{\partial \psi^{\prime}}{\partial \lambda} \frac{\partial \psi^{\prime}}{\partial \phi}-\psi^{\prime} \frac{\partial^{2} \psi^{\prime}}{\partial \lambda \partial \phi}\right)+\frac{V}{a^{2}}\left[\left(\frac{\partial \psi^{\prime}}{\partial \phi}\right)^{2}-\psi^{\prime} \frac{\partial^{2} \psi^{\prime}}{\partial \phi^{2}}\right]\end{array}\right\}$ 
SLP

(a) CMIP5 inter-model regression

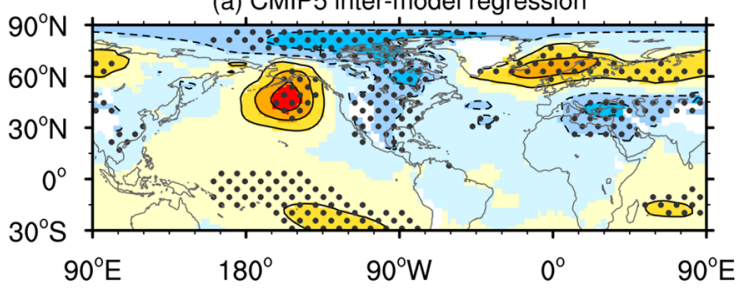

(c) CAM4

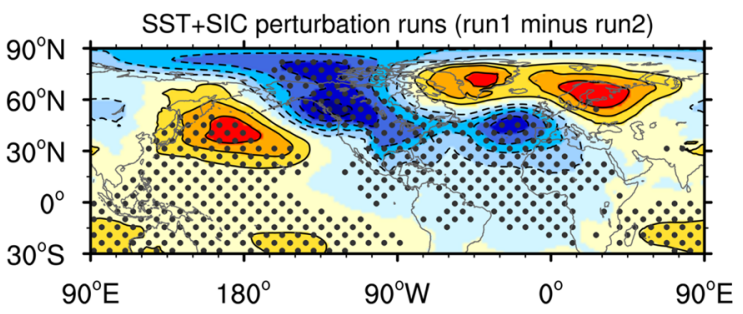

(e) IFS

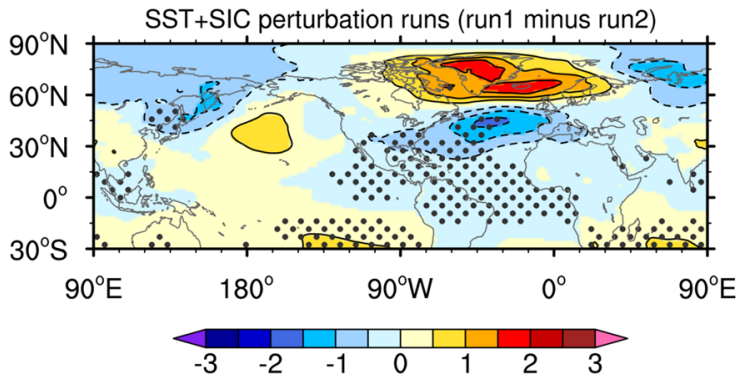

Fig. 5 Assessing the uncertainty in the DJF forced response of (left) SLP (contour interval: $0.5 \mathrm{hPa}$ ) and (right) $250-\mathrm{hPa}$ geopotential height (contour interval: $10 \mathrm{~m}$ ) associated with $\mathrm{PA}_{\Delta \mathrm{SLP}}$. $\mathbf{a}-\mathbf{b}$ Intermodel regression of the forced response against $\mathrm{PAI}_{\triangle \mathrm{SLP}}$ across the ten CMIP5 models. $\mathbf{c}-\mathbf{f}$ the AGCM response in the SST+SIC per-

related to the zonal-mean meridional cells, the air-sea interaction, and the midlatitude Rossby wavetrain.

From the zonal-mean perspective, $\mathrm{SST}_{\Delta \mathrm{SLP}}$ represents anomalous warming in the Northern Hemisphere and anomalous cooling in the Southern Hemisphere (Fig. 4a, d). This SST pattern is associated with more zonal-mean precipitation in the northern tropics and less zonal-mean precipitation in the southern tropics, i.e., strengthening and weakening of the inter-tropical convergence zone (ITCZ) in the Northern Hemisphere and Southern Hemisphere, respectively (Fig. 6a). The change in ITCZ is associated with 10-20\% weakening of the Hadley circulation except in the upper troposphere (Fig. 6a), where the DJF climatological Hadley cell represents a circulation from the Southern Hemisphere to the Northern Hemisphere. The northern hemisphere Ferrel and polar cells also slightly weaken (Fig. 6a).

As mentioned in introduction, previous studies have shown a large inter-model spread in the global warming due to different climate sensitivities of climate models that have
$\mathbf{Z}_{250}$

(b) CMIP5 inter-model regression

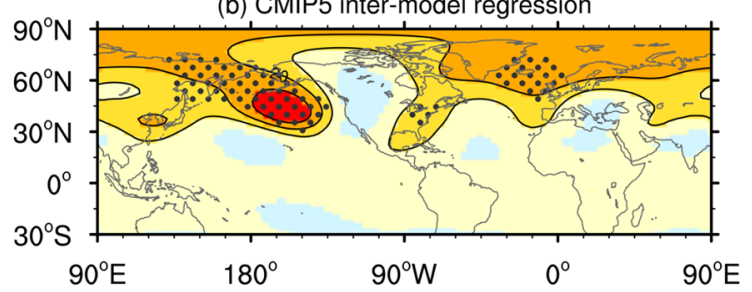

(d) CAM4

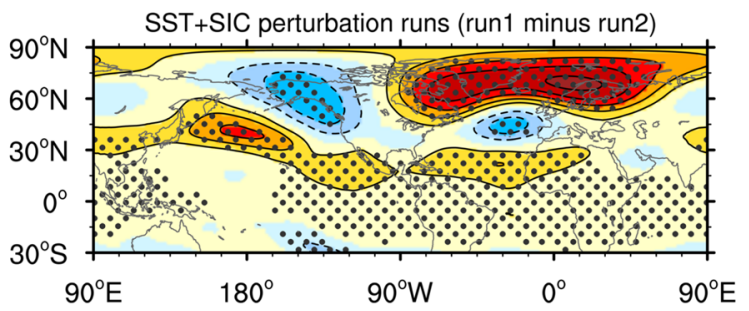

(f) IFS

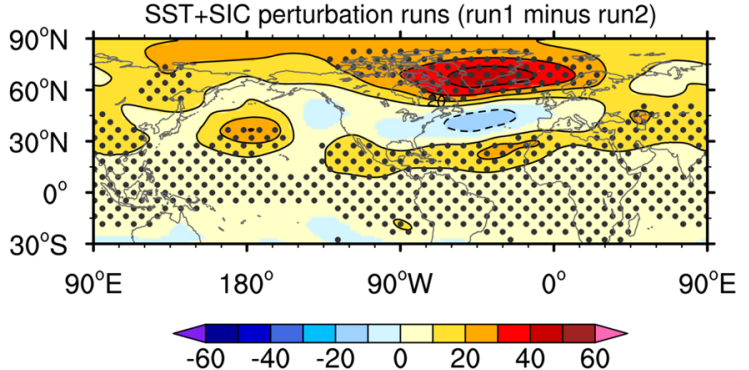

turbation runs (run1 minus run2): (c)-(d) CAM4, (e)-(f) IFS. Unit: $\mathrm{hPa}$. Stippling indicates the $90 \%$ confidence level in the CMIP5 intermodel regression, and the $95 \%$ confidence level in AGCM experiments based on the two-tailed Student's $t$-test

been related to tropical upper-tropospheric warming driven by moist convective processes. A simple check indicates that the circulation uncertainty described above is weakly related to climate sensitivity: $\mathrm{PA}_{\triangle \mathrm{SLP}}$ is weakly related to the forced response in the zonal-mean upper-tropospheric temperature $\left(<0.2{ }^{\circ} \mathrm{C}\right.$; Fig. S6a) and the global-mean surface temperature. In other words, the circulation uncertainties described by $\mathrm{PA}_{\Delta \mathrm{SLP}}$ are unlikely driven by the forcing related to global warming.

Regionally, $\mathrm{SST}_{\triangle \mathrm{SLP}}$ over the tropical region is strongest in the eastern Pacific (Fig. 4a). The stronger warming over the tropical eastern Pacific accompanies stronger local convection and precipitation $\left(\sim 10^{\circ}-15^{\circ} \mathrm{N}\right.$ and $150^{\circ}-130^{\circ} \mathrm{W}$; Fig. 7a). These accompany lower velocity potential and stronger divergent wind at the $250 \mathrm{hPa}$ directing from the tropical region to the midlatitudes in the eastern North Pacific (Fig. 7b). The convergent wind is associated with a cyclonic (i.e., positive sign) Rossby wave source $\left(\sim 40^{\circ} \mathrm{N}, 135^{\circ} \mathrm{W}\right.$; Fig. $\left.7 \mathrm{c}\right)$. Meanwhile, the 
(a) CMIP5 inter-model regression

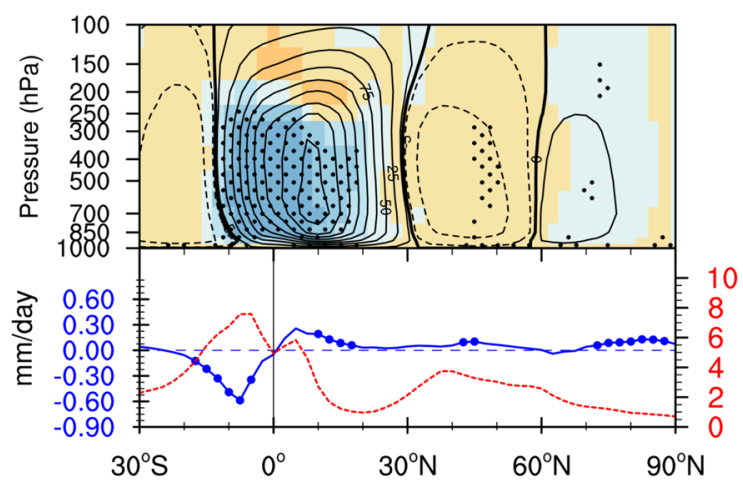

(b) Response in CAM4

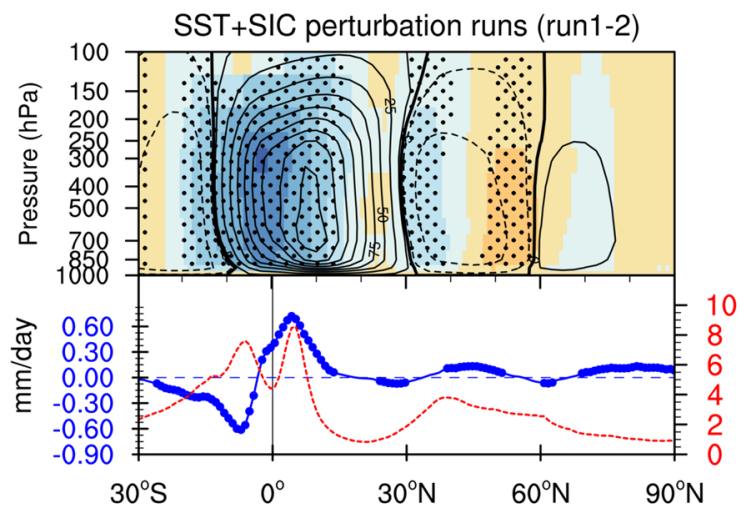

(c) Response in IFS

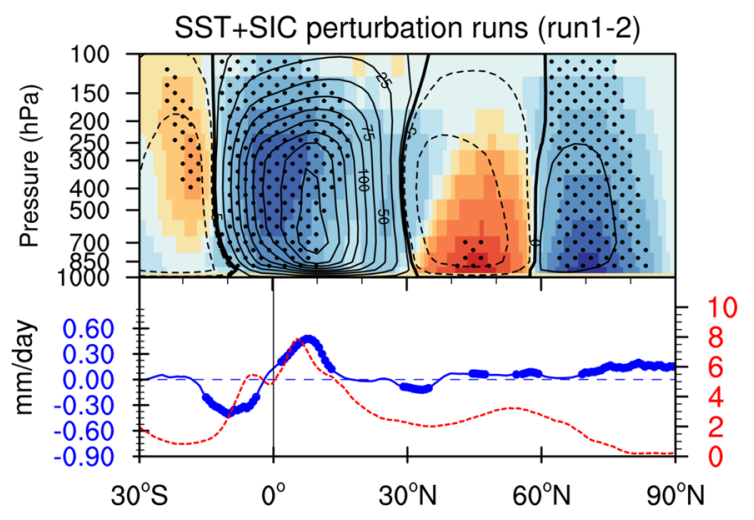

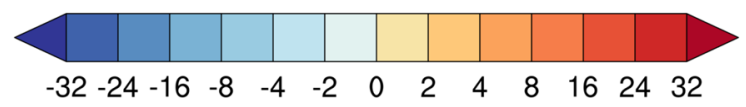

Fig. 6 Assessing the uncertainty in the DJF forced response of the zonal-mean mass streamfunction $\left(10^{9} \mathrm{~kg} \mathrm{~s}^{-1}\right)$ and the zonal-mean precipitation $\left(\mathrm{mm} \mathrm{day}^{-1}\right)$ associated with $\mathrm{PA}_{\Delta \mathrm{SLP}}$. a Inter-model regression of the forced response against $\mathrm{PAI}_{\triangle \mathrm{SLP}}$ across the ten CMIP5 models, $\mathbf{b}-\mathbf{c}$ the AGCM response in the SST + SIC perturbation runs (run1 minus run2): b CAM4, and c IFS. For figures showing the zonal-mean mass streamfunction, the contour lines indicate the 2069/70-2098/99 DJF climatology in the RCP8.5 scenario, where

region with a large gradient in the velocity potential is associated with an anticyclonic (i.e., negative sign) Rossby wave source over the central North Pacific $\left(\sim 30^{\circ} \mathrm{N}\right.$ and $160-150^{\circ} \mathrm{W}$; Fig. $\left.7 \mathrm{~b}, \mathrm{c}\right)$. The anticyclonic Rossby wave source accompanies the emanation of a Rossby wavetrain from the anomalous anticyclone (Fig. 7c). This wavetrain propagates eastward to an anomalous cyclone over the North American west coast and then propagates southeastward to the Gulf of Mexico $\left(\sim 20^{\circ} \mathrm{N}, 90^{\circ} \mathrm{W}\right.$; Fig. $\left.7 \mathrm{c}\right)$. It appears that the northeastern Pacific SLP uncertainty involves tropical-midlatitude interaction over the Pacific. Moreover, because the wavetrain does not propagate further from North America to the northeastern Atlantic, the local air-sea interaction appears to be important in the northeastern Atlantic SLP uncertainty. the thick lines indicate 0 , the solid and dashed lines indicate the contours $\pm 5 \times 10^{9} \mathrm{~kg} \mathrm{~s}^{-1}$ and the multiples of $\pm 25 \times 10^{9} \mathrm{~kg} \mathrm{~s}^{-1}$. For figures showing the zonal-mean precipitation, blue line indicates the CMIP5 inter-model regression or the AGCM response, and red line indicates the 2069/70-2098/99 DJF climatology. Stippling and blue dots denotes the grid points exceeding the $95 \%$ confidence interval of the zonal-mean mass streamfunction and the zonal-mean precipitation, respectively

\subsection{Atmospheric impact of the SST + SIC uncertainty patterns}

Next, we use AGCM experiments to assess the extent to which the SST and SIC drive PA ${ }_{\triangle S L P}$ and whether the mechanisms identified in Sect. 4.1 (e.g., weakening of the Hadley cell, the tropical-midlatitude interaction, and the Rossby wave propagation) hold. The SLP response of CAM4 in the SST + SIC perturbation runs has a positive center over the midlatitude North Pacific $\left(\sim 40^{\circ} \mathrm{N}, 180^{\circ}\right)$ and a dipole pattern over the North Atlantic (Fig. 5c). The pattern has features similar to the CMIP5 inter-model regression although the positive and negative centers shift westward (Fig. 5 c vs. Fig. 5a); the possible reason causing the westward shift will be studied later in this section. 
CMIP5 inter-model regression

(a) Precipitation (shading)

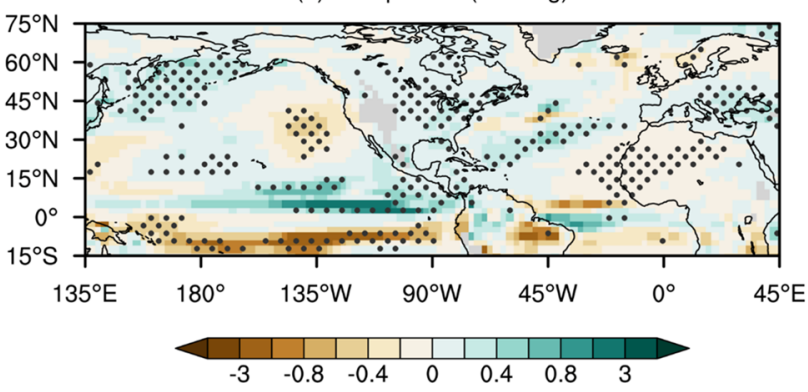

(b) 250-hPa vp (contour), div wind (vector) and RWS (shading)

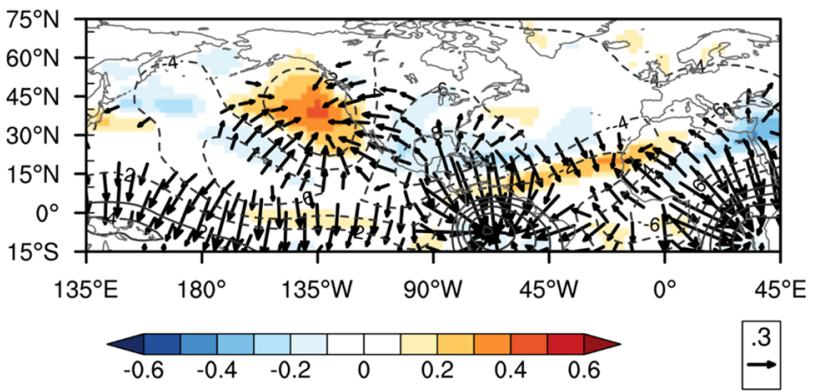

(c) 250-hPa eddy Z (contour), WAF (vector) and RWS (shading)

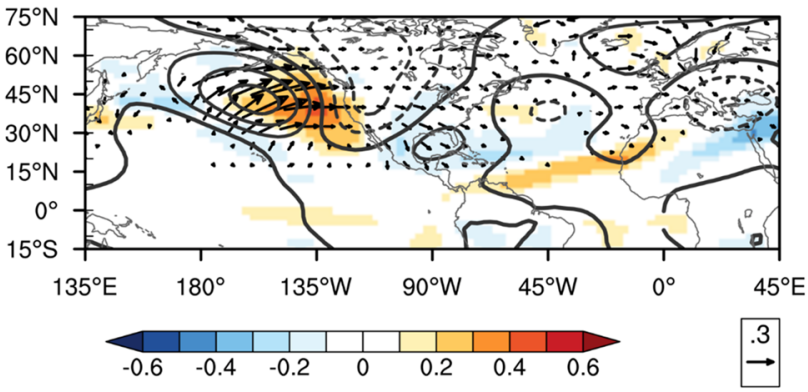

Fig. 7 Inter-model regression of the forced response against $\mathrm{PAI}_{\triangle \mathrm{SLP}}$ across the ten CMIP5 models. a Precipitation (shading; mm day ${ }^{-1}$ ). b $250-\mathrm{hPa}$ velocity potential (contour; $10^{5} \mathrm{~m}^{2} \mathrm{~s}^{-1}$ ), divergent wind (vector; $\mathrm{m} \mathrm{s}^{-1}$ ), and Rossby wave source (shading; $10^{-11} \mathrm{~s}^{-2}$ ). c 250$\mathrm{hPa}$ eddy geopotential height (contour interval: $10 \mathrm{~m}$ ) and horizontal component of wave activity fluxes (vector; $\mathrm{m}^{2} \mathrm{~s}^{-2}$ ), and Rossby wave source (shading; $10^{-11} \mathrm{~s}^{-2}$ ) Stippling in (a) indicates the 95\% confidence level

The pattern correlation between the CAM4 SLP response and the SLP inter-model regression pattern from the ten CMIP5 models increases from +0.381 to +0.731 when the CAM4 SLP response is shifted zonally by $35^{\circ}$. The positive pressure responses over the North Pacific and the North Atlantic also have an equivalent barotropic structure (Fig. 5c, d). On the other hand, the SLP and 250-hPa height response of IFS is generally weaker than CAM4, with a positive response centered at the central North Pacific $\left(\sim 40^{\circ} \mathrm{N}, 180^{\circ}\right)$ and a dipole-like structure over the North Atlantic (Fig. 5e, f). In short, CAM4 and IFS tend to simulate coherent atmospheric responses over the oceans. Comparatively, the CAM4 response is closer to the intermodel regression from the ten CMIP5 models, and the IFS response is weaker, especially over the North Pacific. We will show that the CAM4 response has mechanisms closer to the CMIP5 inter-model difference than the IFS response.

The zonal-mean response of the two AGCMs shows suppressed precipitation in the southern tropics and enhanced precipitation in the northern tropics, representing an enhanced ITCZ over the Northern Hemisphere (Fig. 6b, c). These precipitation responses are unlikely driven by the moist convective processes because the response in uppertropospheric warming is weak (Fig. S6b,c). Moreover, the two AGCMs simulate substantial weakening in the Hadley cell between $10^{\circ} \mathrm{S}$ and $10^{\circ} \mathrm{N}$ (Fig. 6b, c), implying weaker atmospheric poleward heat transport in the Northern Hemisphere (Kang et al. 2009; Schneider et al. 2014; Chen et al. 2021). The tropical zonal-mean circulation responses of the two AGCMs are generally consistent with the inter-model regression from the ten CMIP5 models. In mid- and high-latitudes, CAM4 simulates a weak response in Ferrel and Polar cells, where the southern (northern) edge of the Ferrel cell is enhanced (weakened) (Fig. 6b). On the other hand, IFS simulates more substantial weakening in Ferrel and polar cells (Fig. 6c). The center of these responses is located at $45^{\circ} \mathrm{N}$ and $65^{\circ} \mathrm{N}$, respectively (Fig. 6c), which coincides with the two centers of the dipole-like response in the Atlantic (Fig. 5e, f). Therefore, IFS has a stronger response in the zonal-mean circulation than CAM4 and the CMIP5 intermodel difference.

Regionally, in CAM4, the Rossby wavetrain response from the North Pacific to the North Atlantic (Fig. 8e) is associated with strong tropical-midlatitude interaction at $180^{\circ}-135^{\circ} \mathrm{W}$ over the North Pacific (Fig. 8c), which is related to the enhanced tropical rainfall over the tropical eastern Pacific $\left(0^{\circ}-15^{\circ} \mathrm{N}\right.$ and $180^{\circ}-90^{\circ} \mathrm{W}$; Fig. $\left.8 \mathrm{a}\right)$. The wave activity fluxes propagate northeastward from the North Pacific to North America, and then the propagation turns eastward to the high-latitude North Atlantic (Fig. 8e). The Rossby wavetrain response emanates from the regions with an anticyclonic Rossby wave source at $30^{\circ}-40^{\circ} \mathrm{N}$ and $150^{\circ} \mathrm{E}-165^{\circ} \mathrm{W}$ over the western-central North Pacific and at $\sim 15^{\circ} \mathrm{N}$ and $150^{\circ}-135^{\circ} \mathrm{W}$ over the northeastern Pacific; these sources are due to a larger gradient in the velocity potential (Fig. 8c; the third and fourth terms in Eq. 1). Compared to the inter-model regression from the ten CMIP5 models, the Rossby wavetrain response in CAM4 shifts westward (Figs. 8e vs. 7c). Although the significant tropical rainfall response in CAM4 is extended westward from $\sim 155^{\circ} \mathrm{W}$ to $180^{\circ}$ (Figs. 8 a vs. $7 \mathrm{a}$ ), the associated divergent wind response over the tropical Pacific is not shifted westward (Figs. 8c vs. 7b). Therefore, the westward extension of the 
Response in SST+SIC perturbation runs (run1-2)

(a) CAM4

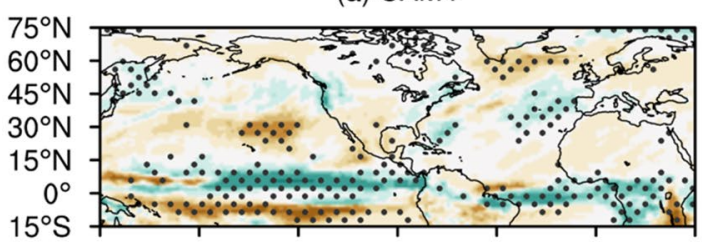

(a)-(b) Precipitation (shading) (b) IFS

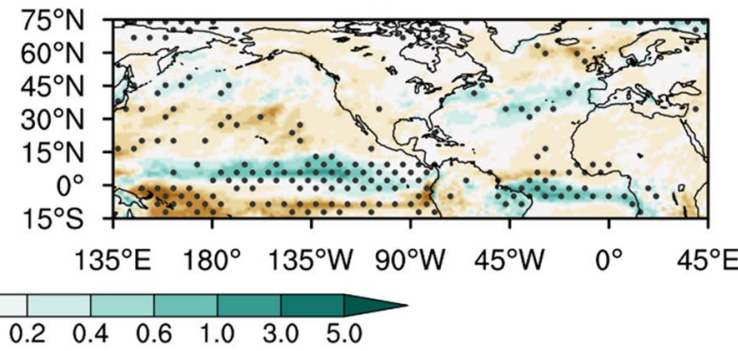

(c)-(d) 250-hPa vp (contour), div wind (vector) and RWS (shading)

(c) $\mathrm{CAM} 4$

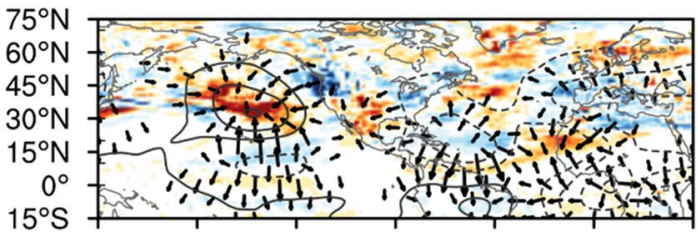

(d) IFS

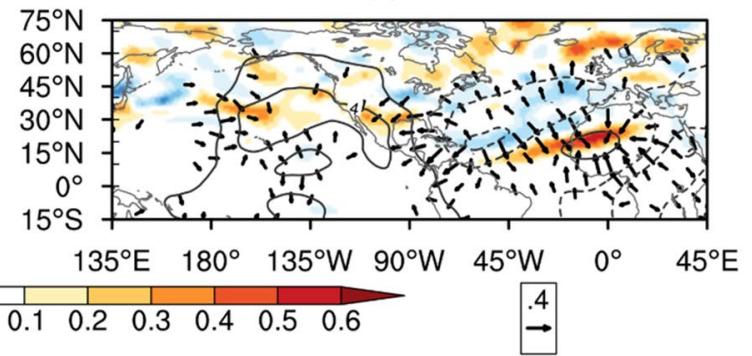

(e)-(f) 250-hPa eddy $Z$ (contour), WAF (vector) and RWS (shading)

(e) CAM4

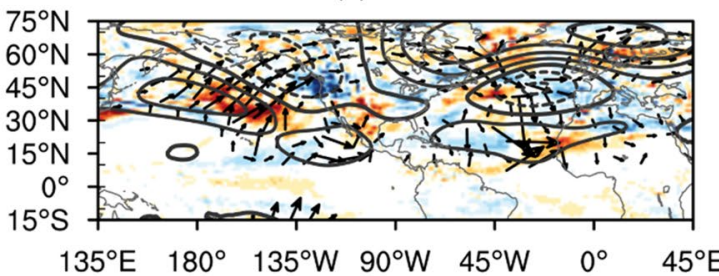

(f) IFS

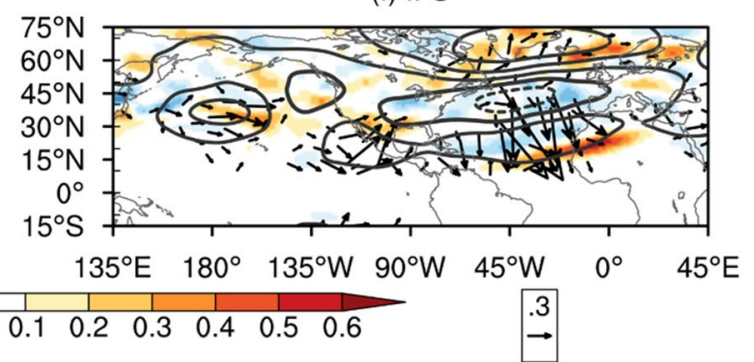

Fig. 8 As in Fig. 7, but for the (left) CAM4 and (right) IFS responses in the SST + SIC perturbation runs

precipitation response in CAM4 cannot explain the westward shift of the Rossby wavetrain response in CAM4 relative to the CMIP5 inter-model difference.

Indeed, the midlatitude Northwestern Pacific $\left(\sim 30^{\circ}-40^{\circ} \mathrm{N}\right.$ and $150^{\circ}-165^{\circ} \mathrm{E}$, where the Rossby wavetrain emanates) has an easterly wind response, which can be explained by the non-linear forcing by transient eddies that is not considered in Eq. (1). Specifically, convergence of the lowfrequency (8-day low-pass filtered) $\mathbf{E}$ vector propagating westward from the northeastern Pacific $\left(\sim 30^{\circ}-45^{\circ} \mathrm{N}\right.$ and $\left.160^{\circ}-150^{\circ} \mathrm{W}\right)$ corresponds to the easterly wind response at northwestern Pacific (Hoskins et al. 1983; Fig. S7a). The high-frequency eddy forcing is much weaker than the lowfrequency eddy forcing (Fig. S7a,b). The westward pointing low-frequency $\mathbf{E}$ vector over the midlatitude North Pacific may explain the westward shift of the geopotential height response and the associated Rossby wavetrain response. In short, the Rossby wavetrain response in CAM4 is related to the tropical-midlatitude interaction and the low-frequency transient eddy forcing. Note that the local air-sea interaction may also be important in the North Atlantic circulation response, because there is limited wave propagation from the North Pacific to the North Atlantic (Fig. 8e). Apart from the low-frequency transient eddy forcing, the mechanisms of CAM4 are similar to the CMIP5 inter-model difference.

In IFS, the Rossby wavetrain response over the North Atlantic is separated from the response over the North Pacific. The Rossby wavetrain response over the North Pacific in IFS is much weaker than that in CAM4 (Figs. 8f vs. 8e); this is related to weaker responses of tropical precipitation and tropical-midlatitude interaction (Figs. 8b, d vs. $8 \mathrm{a}, \mathrm{c})$. The wave activity fluxes over the North Atlantic are emanated from the region with anticyclonic Rossby wave source $\left(\sim 40^{\circ}-45^{\circ} \mathrm{N}\right.$ and $45^{\circ}-20^{\circ} \mathrm{W}$; Fig. 8f). The emanation 


\section{DJF response of SLP (left) and $Z_{250}$ (right) in CAM4}

(a) SST perturbation runs (run3 minus run4)

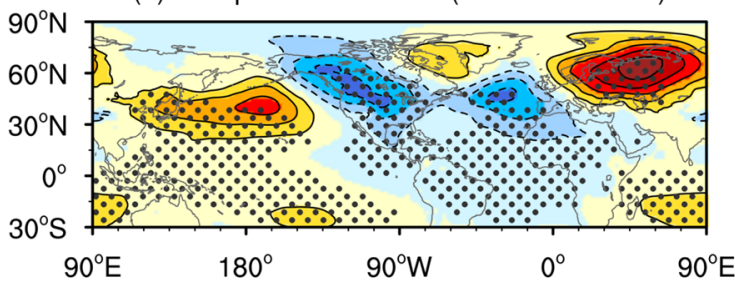

(c) SIC perturbation runs (run5 minus run6)

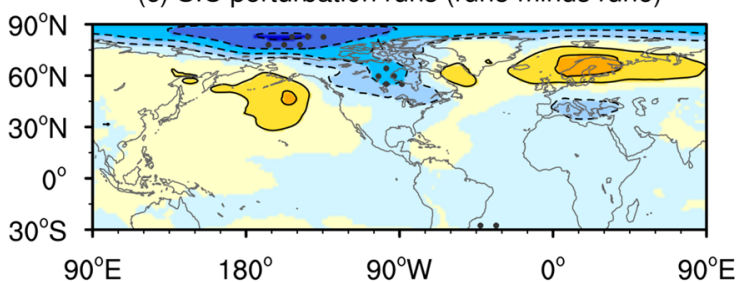

(e) $=(\mathrm{a})+(\mathrm{c})$ (shading), SST + SIC (contour)

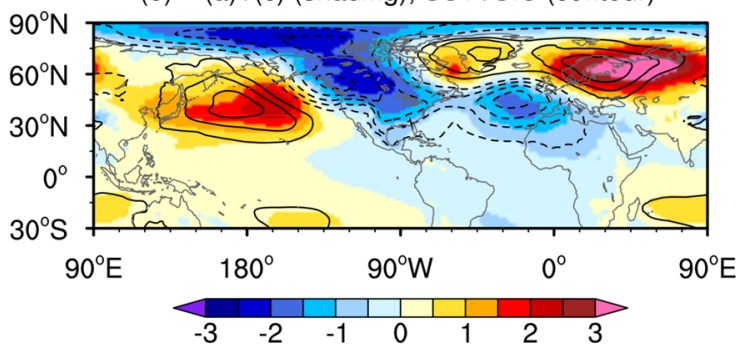

Fig. 9 DJF response of (left) SLP (contour intevrval: $0.5 \mathrm{hPa}$ ) and (right) $250-\mathrm{hPa}$ geopotential height (contour interval: $10 \mathrm{~m}$ ) in CAM4. a-b the SST perturbation runs, and $\mathbf{c}-\mathbf{d}$ the SIC perturbation runs, e-f the response in the SST + SIC perturbation runs (contour)

is associated with enhanced precipitation and stronger divergent wind at $250-\mathrm{hPa}$. This appears to be related to strengthening of the local air-sea interaction at the midlatitude North Atlantic. The role of transient eddies is not investigated due to the lack of data availability. The above results suggest that the responses of CAM4 and IFS to the SST + SIC perturbation have different dynamical mechanisms, where the response of CAM4 is closer to the CMIP5 inter-model difference.

\subsection{Separate impact of the SST and SIC uncertainty patterns}

The SLP response in the SST + SIC perturbation runs of the AGCMs is not fully consistent with the forced SLP response from ten CMIP5 models. The CAM4 response has a spatial pattern similar to the CMIP5 inter-model difference albeit with a zonal shift, whereas the IFS response is generally weaker than CAM4 and is associated with different dynamic mechanisms. The SST perturbation and/or (b) SST perturbation runs (run3 minus run4)

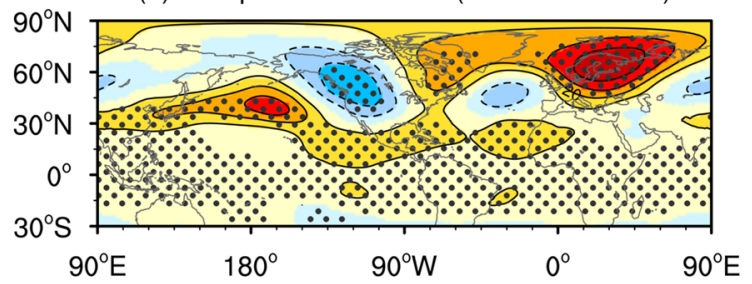

(d) SIC perturbation runs (run5 minus run6)

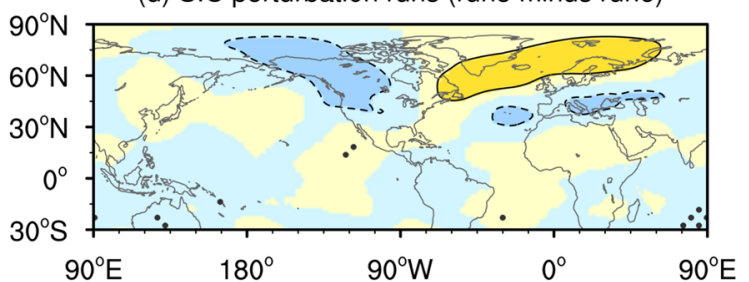

(f) $=(\mathrm{b})+(\mathrm{d})$ (shading), SST + SIC (contour)

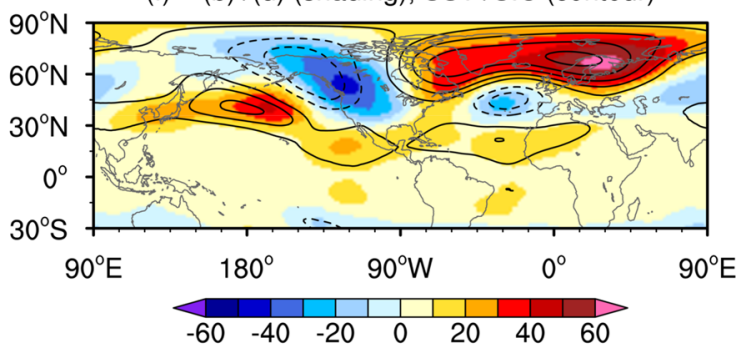

and the sum of responses in the SST perturbation runs and the SIC perturbation runs (shading). In a-d, stippling indicates the $95 \%$ confidence level based on the two-tailed Student's $t$-test

the SIC perturbation could contribute to the difference in the SLP response between the AGCMs and CMIP5 models, as well as the difference between the two AGCMs. Hence, it is instructive to know the influence of the SST and SIC perturbation runs separately on the SLP response in the SST + SIC perturbation runs (Figs. 8a-d and 9a-d), and to know whether the responses to these perturbations are linear (Figs. 8e, f and 9e, f). The impact is predominantly linear when the SST + SIC response is equal to the sum of the individual responses of SST and SIC.

For CAM4, the linear sum of pressure responses in the SST perturbation runs and the SIC perturbation runs (shading in Fig. 9e, f) is broadly similar to the pressure responses in the SST + SIC perturbation runs (contour in Fig. 9e, f). The similarity suggests that the pressure responses of CAM4 in the SST + SIC perturbations can be mainly linearly explained by their SST and SIC components. Specifically, the pressure responses of CAM4 in the SST + SIC perturbations are explained primarily by the SST perturbation, except for the region with sea ice (Figs. 9a vs. 9e). The positive 


\section{DJF response of SLP (left) and $Z_{250}$ (right) in IFS}

(a) SST perturbation runs (run3 minus run4)

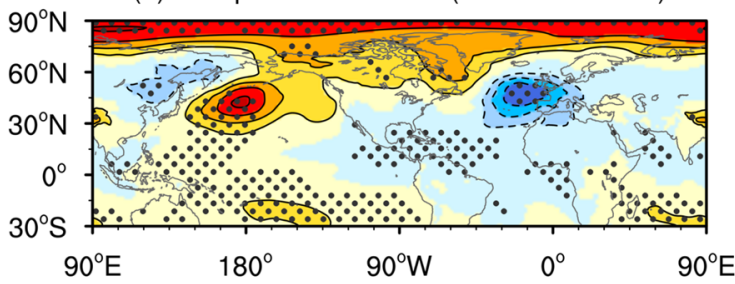

(c) SIC perturbation runs (run5 minus run6)

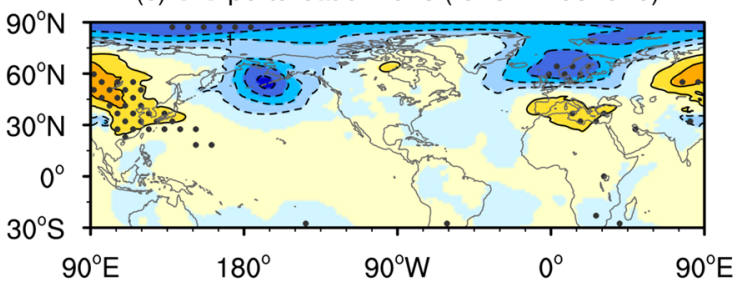

(e) $=(\mathrm{a})+(\mathrm{c})$ (shading), SST + SIC (contour)

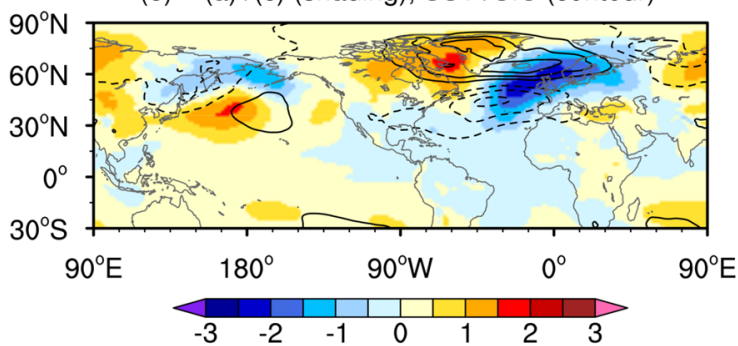

(b) SST perturbation runs (run3 minus run4)

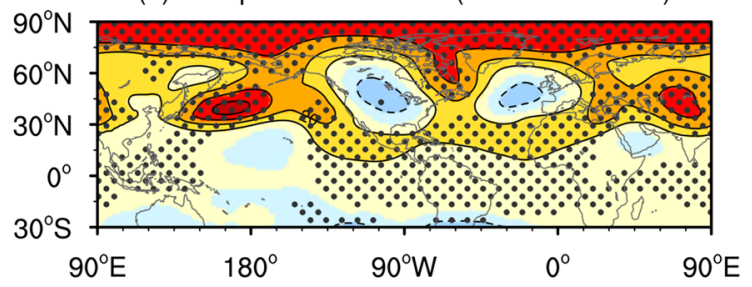

(d) SIC perturbation runs (run5 minus run6)

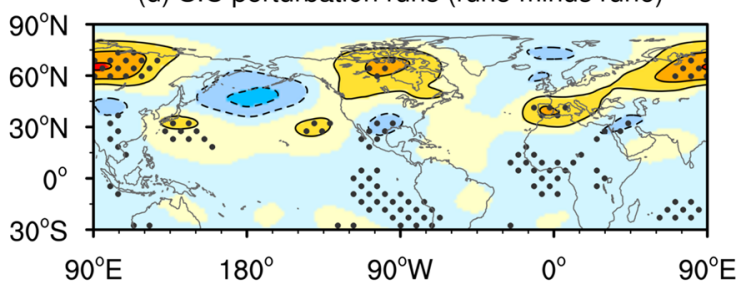

$(f)=(b)+(d)$ (shading), SST + SIC (contour)

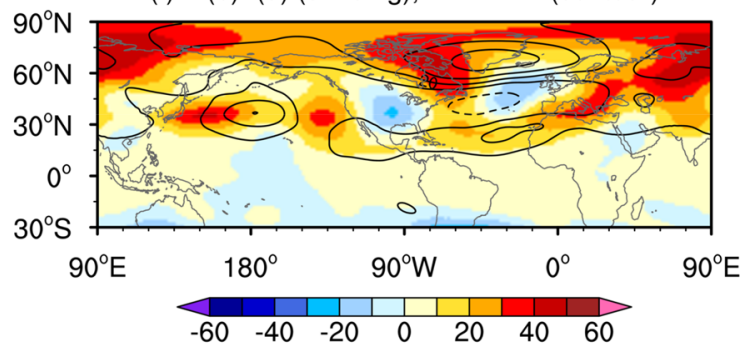

Fig. 10 As in Fig. 9, but for the response in IFS

pressure response over the high-latitude Euro-Atlantic region $\left(\sim 60^{\circ}-80^{\circ} \mathrm{N}\right.$ and $\left.90^{\circ} \mathrm{W}-45^{\circ} \mathrm{E}\right)$ in the SST + SIC perturbation runs (contour in Fig. 9e, f) is split into two centers over the Baffin Bay $\left(\sim 75^{\circ} \mathrm{N}, 70^{\circ} \mathrm{W}\right)$ and the Barents-Kara Sea $\left(\sim 60^{\circ} \mathrm{N}, 50^{\circ} \mathrm{E}\right)$ in the SST perturbation runs (Fig. 9a, b). Both SST and SIC perturbations contribute to the positive pressure response near Greenland (part of the dipole-like response) (Fig. 9a, c). The SIC perturbation is the dominant factor of the Arctic SLP response, and it contributes to the negative SLP response over the Canadian Archipelago (Fig. 9c). Note that the pressure responses to the SIC perturbation have smaller signal-to-noise ratios than those responses to the SST perturbation (as indicated by a less statistically significant response).

For IFS, the pressure response pattern in the SST perturbation runs is closer to that in the SST + SIC perturbation runs than the SIC perturbation runs, but the patterns differ (top panel in Fig. 10 vs. contour in the bottom panel in Fig. 10). The weak pressure responses over the Arctic (north of $\left.75^{\circ} \mathrm{N}\right)$ and the midlatitude North Pacific $\left(\sim 30^{\circ}-60^{\circ} \mathrm{N}\right)$ in the SST + SIC perturbation runs (contour in Fig. 10e, f) are the result of the opposite effect of the SST perturbation (Fig. 10a, b) and the SIC perturbation (Fig. 10c, d).
However, the linear sum of these pressure responses (shading in Fig. 10e, f) does not resemble the circulation response in the SST + SIC perturbation runs, indicating non-linearity in the response (contour in Fig. 10e, f). Neither SST perturbation nor SIC perturbation can reproduce the dipole-like pressure response over the North Atlantic (Fig. 10a-d). The non-linear effect of the pressure responses to the SST and SIC perturbations is also strong in the high-latitude Eurasia $\left(\sim 60^{\circ}-80^{\circ} \mathrm{N}\right.$ and $\left.45^{\circ}-120^{\circ} \mathrm{E}\right)$. The above results suggest that the pressure response in the SST + SIC perturbation runs of IFS is due to the non-linear effect of the SST and SIC perturbations.

The SLP responses of CAM4 and IFS in the SST perturbation runs are consistent in the North Pacific (Figs. 9a and 10a), and match the sign of the inter-model regression pattern from the ten CMIP5 models albeit with a westward shift (Fig. 5a). This matching is expected because the North Pacific SLP response of the two AGCMs is consistent in the SST + SIC perturbation runs, which is associated with the tropical-midlatitude interaction. Here, the SST perturbation causes substantial weakening in the Hadley cell and a stronger ITCZ in the northern tropics (Fig. 11). Regionally, the rainfall is enhanced in the northern tropical Pacific 
(a) CAM4: SST perturbation runs (run3-4)

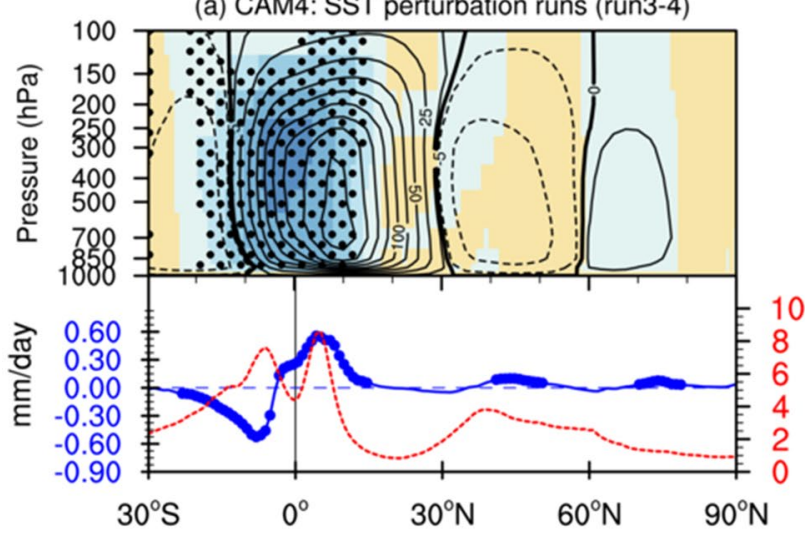

(b) IFS: SST perturbation runs (run3-4)

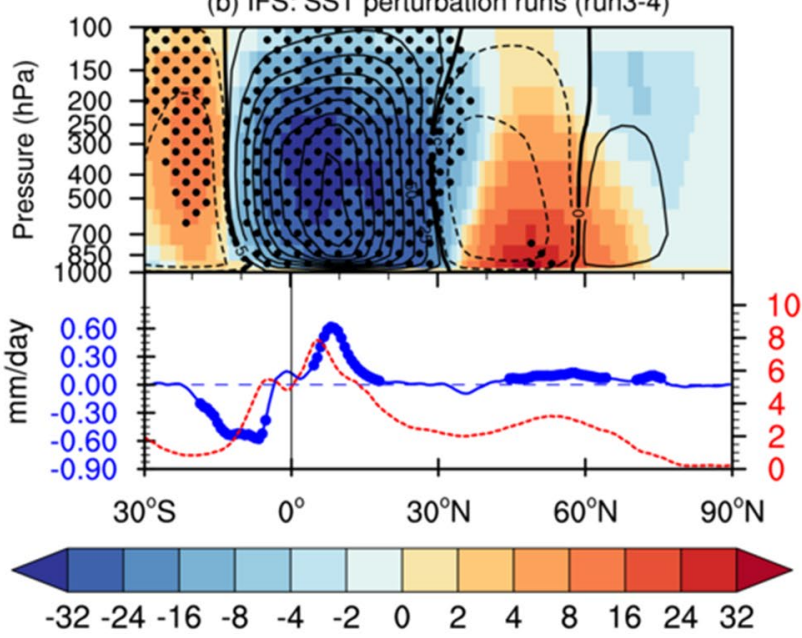

Fig. 11 As in Fig. 6, but for the response of CAM4 and IFS in the SST perturbation runs

$\left(\sim 180^{\circ}-90^{\circ} \mathrm{W}, 0^{\circ}-15^{\circ} \mathrm{N}\right.$; Fig. $\left.12 \mathrm{a}, \mathrm{b}\right)$. This accompanies stronger divergence over the tropics and stronger convergence over the midlatitudes near $180^{\circ}-135^{\circ} \mathrm{W}$ at the $250 \mathrm{hPa}$, representing stronger tropical-midlatitude interaction over the North Pacific (Fig. 12c, d). The anticyclonic Rossby wave source is enhanced at the region with a larger gradient in the velocity potential at $15^{\circ} \mathrm{N}$ (Fig. $12 \mathrm{c}$, d; the third and fourth terms in Eq. 1), and is associated with emanation of the wave activity fluxes from the Pacific to North America (Fig. 12e, f).

Indeed, the wave activity fluxes also emanate from the mid-latitude region with positive eddy height response (Fig. 12e, f). The increase in the eddy height is partly related to the tropical midlatitude interaction near the central North Pacific, where stronger convergent wind corresponds to a cyclonic Rossby wave source (Fig. 12c, d). In CAM4, part of the increase in the eddy height is related to the low-frequency (8-day low-pass filtered) transient eddy forcing, where the convergence of $\mathbf{E}$ vector near $30^{\circ} \mathrm{N}, 180^{\circ}$ corresponds to an easterly wind anomaly associated with the positive height anomaly (Fig. S7c). In IFS, the Rossby wavetrain propagates equatorward from the northwestern Pacific (Fig. 12f), and this is different from the results in its SST + SIC perturbation runs (Fig. 8f) and the CAM4 runs (Fig. 12e). The difference again suggests that the dynamics for the responses of CAM4 and IFS are different. Despite this, the above results suggest that the SST perturbation from the North Pacific contributes to the high-pressure response over the North Pacific and the Rossby wave propagation from the North Pacific to North America. Thus, it appears that the North Pacific SLP uncertainty in the CMIP5 models is related to the SST uncertainty involving tropical-midlatitude interaction.

In addition to the positive SLP response over the North Pacific, the two AGCMs simulate consistently a negative SLP response over the mid-latitude North Atlantic in the SST perturbation runs (Figs. 9a and 10a). However, their responses in the SST perturbation runs are different over the continents and the Arctic. On one hand, IFS has a stronger response of the zonal-mean mass streamfunction to the SST perturbation than CAM4, where the Ferrel and polar cells weaken and shift northward albeit not statistically significant (Fig. 11b). The associated weakening of the rising motion in the subpolar latitudes around $70^{\circ} \mathrm{N}$ is accompanied by an increase in pressure over the subpolar region across the Canadian Archipelago and the North Atlantic (Fig. 10a, b). On the other hand, CAM4 does not have responses in the Ferrel and polar cells to the SST perturbation (Fig. 11a); its midlatitude circulation response is mainly explained by the wavetrain response (Fig. 12e).

Neither the SST perturbation nor the SIC perturbation explains the entire dipole-like SLP response over the North Atlantic in the SST + SIC perturbation runs. In response to the SIC perturbation, the two AGCMs simulate consistently a negative SLP response over the Arctic (Fig. 9e and 10e). However, their response outside the Arctic diverges, including over the North Pacific, Scandinavia and the Mediterranean. That is, the difference in these SLP responses between the two AGCMs is statistically significant. There is also no consistent response in the meridional circulations (figures not shown). Although previous studies suggested that the midlatitude circulation response to SIC could be amplified by the stratosphere (Zhang et al. 2018; De and Wu 2019), the stratospheric circulation response to SIC in the two AGCMs is weak (Fig. S8). Because SIC does not consistently influence the midlatitude circulation in the sensitivity experiments, we do not analyze in-depth the regional circulation features over the mid-latitudes and the associated dynamics. In short, the North Atlantic dipole-like SLP uncertainty in CMIP5 models is related to the combined influence of SST and SIC perturbations. The direct impact of the SIC uncertainty on the midlatitude circulation could be investigated 
Response in SST perturbation runs (run3-4)

(a) CAM4

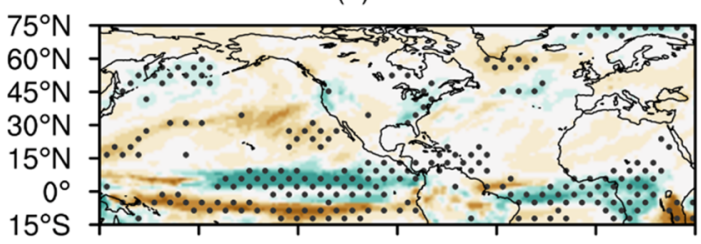

(a)-(b) Precipitation (shading)

$135^{\circ} \mathrm{E} \quad 180^{\circ} \quad 135^{\circ} \mathrm{W} \quad 90^{\circ} \mathrm{W} \quad 45^{\circ} \mathrm{W} \quad 0^{\circ} \quad 45^{\circ} \mathrm{E}$

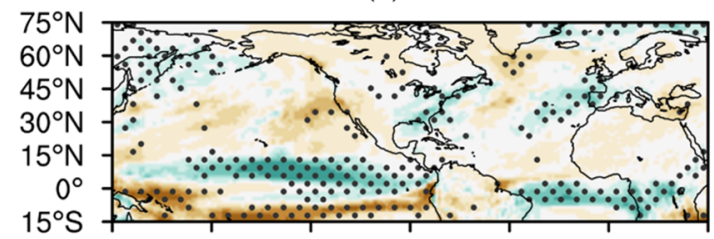

$135^{\circ} \mathrm{E} \quad 180^{\circ} \quad 135^{\circ} \mathrm{W} \quad 90^{\circ} \mathrm{W} \quad 45^{\circ} \mathrm{W} \quad 0^{\circ} \quad 45^{\circ} \mathrm{E}$

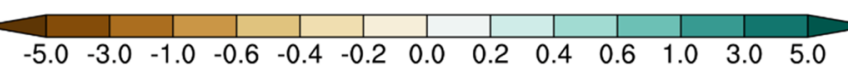

(c)-(d) 250-hPa vp (contour), div wind (vector) and RWS (shading)

(c) CAM4

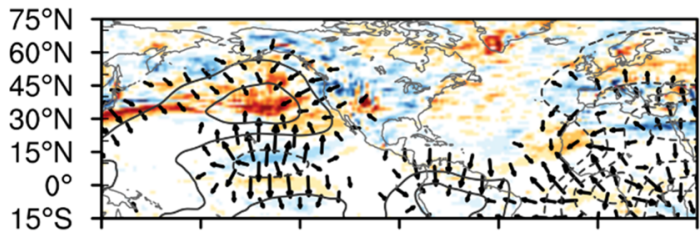

(d) IFS

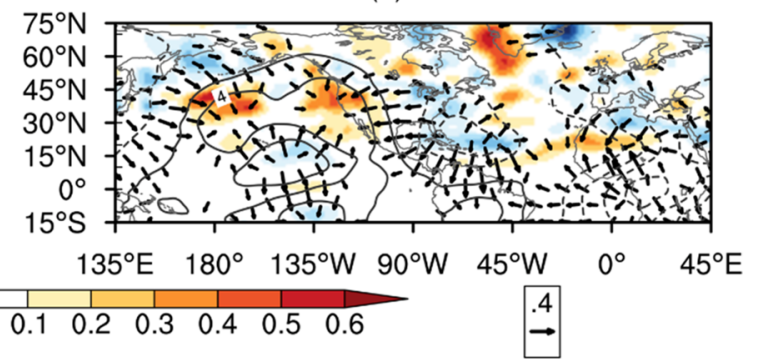

(e)-(f) 250-hPa eddy Z (contour), WAF (vector) and RWS (shading)

(e) CAM4

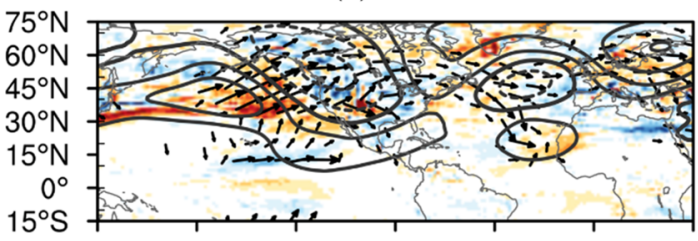

(f) IFS

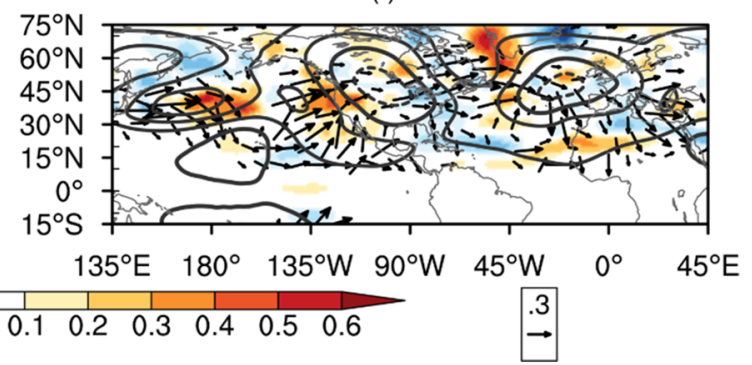

Fig. 12 As in Fig. 7, but for the response in the SST perturbation runs: (left) CAM4 and (right) IFS

by more high-top models with large ensembles in future (Charlton-Perez et al. 2013; Peings et al. 2021).

\section{Summary and conclusions}

\subsection{Summary}

To understand how much SST and SIC contribute to uncertainties in the future projections of boreal winter atmospheric circulation we have implemented a three-tiered approach (Fig. 3). We have identified a pattern that characterizes the dominant uncertainty in the forced SLP response of ten CMIP5 models ( $\left.\mathrm{PA}_{\Delta \mathrm{SLP}}\right)$. The centers of action of the SLP uncertainty are located at the northeastern Pacific and the northeastern Atlantic. The positive sign of PA ${ }_{\Delta S L P}$ is associated with (i) increasing SLP over the northeastern Pacific and decreasing SLP over the North American continent, (ii) increasing SLP over the northeastern Atlantic and Scandinavia and decreasing SLP near the Mediterranean, (iii) decreasing SLP over the Arctic. This pattern also covaries with the uncertainty in the forced response of the interhemispheric SST gradient, the zonal SST gradient over the equatorial Pacific and the total Arctic sea ice extent. We have analyzed the dynamics underlying $\mathrm{PA}_{\Delta \mathrm{SLP}}$ and performed sensitivity experiments with two AGCMs to identify forcing from corresponding global SST and Arctic SIC patterns. Agreement between CMIP5 and AGCM results indicates a potential to narrow uncertainties through better simulating future SST and SIC patterns, while disagreement indicates 
uncertainties from the atmospheric models not represented by the ten CMIP5 models (Sec. 3.1).

In general, the SLP uncertainties over the North Pacific and the North Atlantic in the ten CMIP5 models can be broadly reproduced by the AGCM experiments with prescribed SST and SST/SIC. However, the simulated responses in the two AGCMs differ substantially over continental regions and in response to SIC. The main results are summarized as follows:

\subsubsection{Ocean-atmosphere interaction associated with the North Pacific SLP response}

In the ten CMIP5 models the North Pacific SLP response is associated with the tropical-midlatitude interaction. Such a SLP response can be better explained by the SST perturbation, except that the response in two AGCMs is shifted westward. In these AGCM simulations and the ten CMIP5 models, the SLP response is associated with weakening in the Hadley cell and an enhancement of ITCZ in the Northern Hemisphere, where rainfall is enhanced over the tropical northeastern Pacific with anomalous SST warming. The rainfall response accompanies stronger divergent flow in the tropical northeastern Pacific and stronger convergent flow in the midlatitude North Pacific. The stronger convergent flow is partly related to the positive SLP response over the North Pacific. The anticyclonic Rossby wave source is enhanced in the region with a stronger gradient in velocity potential, which is associated with a Rossby wavetrain propagating eastward towards North America. The westward shift of the SLP response in CAM4 relative to the CMIP5 forced response is found to be related to the low-frequency transient eddy forcing.

The total SLP response of IFS in the SST + SIC perturbation runs is not the linear sum of the pressure responses in the SST perturbation runs and the SIC perturbation runs. In contrast, in CAM4 both the SST and SIC perturbation causes positive SLP responses over the midlatitude North Pacific, which is stronger in the SST perturbation runs. Therefore, the North Pacific SLP responses of the two AGCMs in the SST + SIC perturbation runs have different dynamic mechanisms. Whereas the responses of CAM4 are related to the tropical-midlatitude interaction and the low-frequency transient eddy forcing driven by the SST perturbation, the responses of IFS are affected by non-linear dynamics in response to the SST and SIC perturbations. The CAM4 response and its associated dynamics are closer to the CMIP5 inter-model regression, suggesting that the forced SLP uncertainty over the northeastern Pacific from the ten CMIP5 models is associated with the tropical-midlatitude interaction related to the SST uncertainty over the Pacific.

\subsubsection{Dipole-like pressure response over the Euro-Atlantic region}

In the ten CMIP5 models, the dipole-like SLP response in the North Atlantic appears to result from both local response to SST and remote influences from the Pacific. In CAM4, the SLP responses in the SST perturbation runs and the SST + SIC perturbation runs are similar and again show some correspondence to the ten CMIP5 SLP uncertainty pattern. In these CAM4 simulations, the Rossby wavetrain simulated in the SST perturbation runs is triggered by SST over the Pacific. The triggering is consistent with the results of Delcambre et al. (2013), Ciasto et al. (2016) and Gan et al. (2017). The Atlantic response of CAM4 is located westward relative to the CMIP5 intermodel difference, which is probably related to the westward shift in its Pacific response. On the other hand, IFS also simulates a dipole-like SLP response in the SST + SIC perturbation runs, but such a response is not associated with the Rossby wavetrain propagating from the North Pacific. Rather, the response is associated with local airsea interaction over the midlatitude North Atlantic. The North Atlantic SLP response of IFS in the SST + SIC perturbation runs is not a linear sum of the responses in the SST perturbation runs and the SIC perturbation runs. The non-linear dynamics are crucial in the IFS responses.

Although the dynamics of the North Atlantic SLP response in the two AGCMs are different, both AGCMs simulate the positive SLP response near Greenland and the entire dipole-like response in the SST + SIC perturbation runs only. Thus, the forced SLP uncertainty over the northeastern Atlantic from the ten CMIP5 models appears to be affected by the combined influence of the uncertainty in SST and SIC.

\subsubsection{Diverging midlatitude response to Arctic sea ice}

The SLP responses of the two AGCMs to the SIC perturbation are consistent in the Arctic and show lower SLP associated with less sea ice, as in the ten CMIP5 models. However, the midlatitude SLP response of the two AGCMs diverges. Because the difference in the midlatitude SLP response between the two AGCMs is statistically significant (Fig. S9), we do not expect their midlatitude response to SIC would become consistent even if the simulation is extended to 100 years or longer. Thus, the above results suggest a limited direct impact of SIC on the midlatitudes, consistent with Ogawa et al. (2018). Indeed, the midlatitude circulation could affect the SIC. For example, an extra-tropical anticyclone (e.g., blocking) could enhance the advection of warm air towards the polar region and 
reduces the SIC (Gong and Luo 2017; Svendsen et al. 2018). This linkage could explain the relation in the ten CMIP5 models, but this cannot be verified in an AGCM framework in this study.

\subsection{Conclusions}

The future projection of the winter SLP in the northeastern Pacific and the northeastern Atlantic has a large inter-model spread, which covaries with the large-scale SST gradients and the total Arctic sea ice extent. In this study, sensitivity experiments using CAM4 and IFS have revealed that atmospheric responses to the same SST and SIC perturbation patterns (related to the SLP uncertainties) are generally large, with more coherent responses over the oceans (in terms of the sign of response) than remote regions (especially the continental regions). Specifically, we have learnt the following points:

(1) Possible dynamics responsible for the SLP uncertainty in the ten CMIP5 models:

- The uncertainty in the forced SLP response over the northeastern Pacific is significantly larger than the uncertainty related to internal climate variability. Uncertainties in the SST response to global warming (i.e., SST perturbation) can better explain this uncertainty in SLP, through tropical-midlatitude interaction and the propagation of a Rossby wavetrain towards North America. The relative contribution from the tropical and extratropical Pacific should be investigated in future;

- The uncertainty in the forced SLP response over the northeastern Atlantic is of similar strength as internal climate variability and is even weaker than it at high latitudes. This uncertainty is better explained by the combined effect of SST and SIC perturbations. It appears to be related to a Rossby wavetrain from the North Pacific and with local air-sea interaction, with the first more important in CAM4 and the second more important in IFS. The relative contribution from the inter-basin teleconnection between the North Pacific and the North Atlantic and the local air-sea interaction deserves future work.

(2) The spatial pattern of AGCM simulations is not the same as the CMIP5 inter-model difference. The discrepancy suggests that future projections of the winter SLP might only have slight improvements by constraining only the SST and SIC projections. We should investigate other factors contributing to the inter-model spread in the winter SLP (e.g., differences among
AGCMs and in representing coupled dynamics) in order to provide more accurate climate projections.

(3) The uncertainties over the northern hemisphere continents and at high latitudes appear to depend sensitively on the atmospheric model. Furthermore, the response to SST and SIC perturbations can be non-linear in some models (e.g., IFS), while quite linear in others (e.g., CAM4). Further work is required to understand the uncertainties arising from atmospheric model differences. We should be cautious when using a single climate model to understand the physical mechanism responsible for the uncertainty in future climate projections from multiple models.

One limitation of our study is that the uncertainty in future climate projections is computed from only ten CMIP5 models with only three ensemble members, where these models have more substantial weakening in the Icelandic low than the whole CMIP5 models. The SLP pattern from the inter-model EOF analysis, as well as the corresponding SST and SIC patterns, might also be sensitive to the number of models. Ideally, more models with more ensemble members are required to separate the forced response from the internal climate variability, especially for the northeastern Atlantic and the Arctic. Nevertheless, we believe the results here should motivate further studies to understand the inter-model spread of the future climate projections, e.g. using large ensembles as mentioned in Deser et al. (2020) and Peings et al. 2021. Our results suggest it is important to better assess the relative contribution of tropical and extratropical SST to the spread in future climate projections, as well as the role of the eddy forcing. It is also important to study the role of ocean dynamics (Woollings et al. 2012; Omrani et al. 2016), the troposphere-stratosphere interaction using more high-top models (three out of ten in this study) (Charlton-Perez et al. 2013; Manzini et al. 2014; Omrani et al. 2014; De and Wu 2019), internal climate variability (Deser et al. 2012, 2020) and forced variability to the future climate projections, especially over the North Atlantic and high latitudes.

Supplementary Information The online version contains supplementary material available at https://doi.org/10.1007/s00382-022-06136-0.

Acknowledgements The authors greatly appreciate the constructive comments provided by two anonymous reviewers, which helped improve significantly the quality of manuscript. HNC was supported by the Innovation Group Project of the Southern Marine Science and Engineering Guangdong Laboratory (Zhuhai) (\#311021001), Guangdong Province Key Laboratory for Climate Change and Natural Disaster Studies (Grant No. 2020B1212060025), the National Key Research and Development Program of China (Grant No. 2016YFA0600704) and the National Natural Science Foundation of China (Grant No. 42088101, 41905050); the NordForsk Nordic Centre of Excellence in Arctic Research (\#76654, ARCPATH) supported NK, TK, SY, TT, YG 
and NOE; the NordForsk Nordic-Russian additional funding (\#90077, TRACE) supported NK and YG; the Trond Mohn Foundation (Grant No. BFS2018TMT01; Bjerknes Climate Prediction Unit) supported NK and NOE; in addition, NK acknowledges support from Ministry of Science and Higher Education of the Russian Federation (Agreement No. 075-15-2021-577), and NOE acknowledges support from the Research Council of Norway (\#312017, RACE; \#316618, ROADMAP) through JPI Climate \& JPI Oceans Joint Transnational Call on Next Generation Climate Sciences in Europe for Oceans and Belmont Forum; SQ was supported by the National Natural Science Foundation of China (Grant No. 41905057). Computing resources were provided by UNITETT Sigma AS (NN2343K, NN9390K, NS9015K, NS9064K). The computations with IFS at SMHI were performed on resources provided by the Swedish National Infrastructure for Computing (SNIC) at the National Supercomputing Centre at Linköping University (NSC)

Data availability The CAM4 and IFS data will be available upon request and will be located on the National Infrastructure for Research Data (NIRD) in Norway.

Open Access This article is licensed under a Creative Commons Attribution 4.0 International License, which permits use, sharing, adaptation, distribution and reproduction in any medium or format, as long as you give appropriate credit to the original author(s) and the source, provide a link to the Creative Commons licence, and indicate if changes were made. The images or other third party material in this article are included in the article's Creative Commons licence, unless indicated otherwise in a credit line to the material. If material is not included in the article's Creative Commons licence and your intended use is not permitted by statutory regulation or exceeds the permitted use, you will need to obtain permission directly from the copyright holder. To view a copy of this licence, visit http://creativecommons.org/licenses/by/4.0/.

\section{References}

Andrew T, Gregory J, Webb M, Taylor K (2012) Forcing, feedbacks and climate sensitivity in CMIP5 coupled atmosphere-ocean climate models. Geophys Res Lett 39:L09712. https://doi.org/ 10.1029/2012GL051607

Bader J, Mesquita MDS, Hodges KI, Keenlyside N, Østerhus S, Miles M (2011) A review on Northern Hemisphere sea-ice, storminess and the North Atlantic Oscillation: observations and projeced changes. Atmos Res 101:809-834. https://doi.org/10. 1016/j.atmosres.2011.04.007

Balsamo GP, Beljaars A, Scipal K, Viterbo P, Hurk B, Hirschi M, Betts AK (2009) A revised hydrology for the ECMWF model: Verification from field site to terrestrial water storage and impact in the integrated forecast system. J Hydrometeorology 10:623-643. https://doi.org/10.1175/2008JHM1068.1

Barnes EA, Polvani L (2013) Response of the midlatitude jets, and of their variability, to increased greenhouse gases in the CMIP5 models. J Climate 26:7117-7135. https://doi.org/10.1175/ JCLI-D-12-00536.1

Barnes EA, Screen J (2015) The impact of Arctic warming on the midlatitude jet-stream: Can it? Has it? Will it? Wiley Interdiscip Rev: Climate Change 6:277-286. https://doi.org/10.1002/ wcc. 337

Blackport R, Kushner PJ (2017) Isolating the atmospheric circulation response to Arctic sea ice loss in the coupled climate system. J Climate 30:2163-2185. https://doi.org/10.1175/JCLI-D-16-0257.1
Cattiaux J, Cassou C (2013) Opposite CMIP3/CMIP5 trends in the wintertime Northern Annular Mode explained by combined local sea ice and remote tropical influences. Geophy Res Lett 40:36823687. https://doi.org/10.1002/grl.50643

Chang EKM, Guo Y, Xia X (2012) CMIP5 multimodel ensemble projection of storm track change under global warming. J Geophys Res 117:D23118. https://doi.org/10.1029/2012JD018578

Charlton-Perez A, Baldwin MP, Birner T et al (2013) On the lack of stratospheric dynamical variability in low-top versions of the CMIP5 models. J Geophys Res 118:2494-2505. https://doi.org/ 10.1002 /jgrd .50125

Chen H, Schneider EK, Kirtman BP, Colfescu I (2013) Evaluation of weather noise and its role in climate model simulations. J Climate 26:3766-3784. https://doi.org/10.1175/JCLI-D-12-00292.1

Chen Y-J, Hwang Y-T, Ceppi P (2021) The impacts of cloud radiative changes on poleward atmospheric and oceanic energy transport in a warmer climate. J Climate 34:7857-7874. https://doi.org/10. 1175/JCLI-D-20-0949.1

Cheung HHN, Keenlyside NS, Omrani NE, Zhou W (2018) Remarkable link between projected uncertainties of Arctic sea ice decline and winter Eurasian climate. Adv Atmos Sci 35:38-51. https://doi. org/10.1007/s00376-017-7156-5

Choi J, Lu J, Son SW, Frierson DM, Yoon JH (2016) Uncertainty in future projections of the North Pacific subtropical high and its implication for California winter precipitation change. J Geophys Res Atmos 121:795-806. https://doi.org/10.1002/2015JD023858

Ciasto LM, Li C, Wettstein JJ, Kvamstø NG (2016) North Atlantic storm-track sensitivity to projected sea surface temperature: Local versus remote influences. J Climate 29:6973-6991. https://doi.org/ 10.1175/JCLI-D-15-0860.1

Colfescu I, Schneider EK (2017) Internal atmospheric noise characteristics in twentieth century coupled atmosphere-ocean model simulations. Clim Dyn 49:2205-2217. https://doi.org/10.1007/ s00382-016-3440-9

Colfescu I, Schneider EK, Chen H (2013) Consistency of 20th century sea level pressure trends as simulated by a coupled and uncoupled GCM, Geophys Res. Lett 40:3276-3280. https://doi.org/10.1002/ grl.50545

Collins M, Knutti R, Arblaster J, Dufresne J-L, Fichefet T, Friedlingstein P, Gao X, Gutowski WJ, Johns T, Krinner G, Shongwe M, Tebaldi C, Weaver AJ, Wehner M (2013) Long-term climate change: projections, commitments and irreversibility. In: Stocker TF, Qin D, Plattner G-K, Tignor M, Allen SK, Boschung J, Nauels A, Xia Y, Bex V, Midgley PM (eds) Climate change 2013: the physical science basis. Contribution of Working Group I to the Fifth Assessment Report of the Intergovernmental Panel on Climate Change. Cambridge University Press, Cambridge

De B, Wu Y (2019) Robustness of the stratospheric pathway in linking the Barents-Kara sea variability to the mid-latitude circulation in CMIP5 models. Clim Dyn 53:193-207. https://doi.org/10.1007/ s00382-018-4576-6

Delcambre SC, Lorenz DJ, Vimont DJ, Martin JE (2013) Diagnosing Northern Hemisphere jet portrayal in 17 CMIP3 global climate models: Twenty-first-century projections. J Climate 26:4930 4946. https://doi.org/10.1175/JCLI-D-12-00359.1

Deser C, Phillips A, Bourdette V, Teng H (2012) Uncertainty in climate change projections: The role of internal variability. Clim Dyn 38:527-546. https://doi.org/10.1007/s00382-010-0977-x

Deser C, Tomas RA, Sun L (2015) The role of ocean-atmosphere coupling in the zonal-mean atmospheric response to Arctic sea ice loss. J Climate 28:2168-2186. https://doi.org/10.1175/ JCLI-D-14-00325.1

Deser C, Sun L, Tomas RA, Screen J (2016) Does ocean coupling matter for the northern extratropical response to projected Arctic 
sea ice loss? Geophys Res Lett 43:2149-2157. https://doi.org/10. 1002/2016GL067792

Deser C, Lehner F, Rodgers KB et al (2020) Insights from Earth system model initial-condition large ensembles and future prospects. Nat Climate Change 10:277-286. https://doi.org/10.1038/ s41558-020-0731-2

Ding Q, Wallace JM, Battisti DS, Steig EJ, Gallant AJE, Kim HJ, Geng L (2014) Tropical forcing of the recent rapid Arctic warming in northeastern Canada and Greenland. Nature 509:209-223. https:// doi.org/10.1038/nature132

Döscher R, Acosta M, Alessandri A, Anthoni P, Arneth A, Arsouze T, Bergmann T, Bernadello R, Bousetta S, Caron L-P, Carver G, Castrillo M, Catalano F, Cvijanovic I, Davini P, Dekker E, Doblas-Reyes FJ, Docquier D, Echevarria P, Fladrich U, FuentesFranco R, Gröger M, v. Hardenberg J, Hieronymus J, Karami MP, Keskinen JP, Koenigk T, Makkonen R, Massonnet F, Ménégoz M, Miller PA, Moreno-Chamarro E, Nieradzik L, van Noije T, Nolan P, O'Donnell D, Ollinaho P, van den Oord G, Ortega P, Prims OT, Ramos A, Reerink T, Rousset C, Ruprich-Robert Y, Le Sager P, Schmith T, Schrödner R, Serva F, Sicardi V, Sloth Madsen M, Smith B, Tian T, Tourigny E, Uotila P, Vancoppenolle M, Wang S, Wårlind D, Willén U, Wyser K, Yang S, Yepes-Arbós X, and Zhang Q (2021) The EC-Earth3 Earth system model for the Climate Model Intercomparison Project 6, Geosci Model Dev Discuss, In press. https://doi.org/10.5194/gmd-2020-446

England MR, Polvani LM, Sun L (2020) Robust Arctic warming caused by projected Antarctic sea ice loss. Environ Res Lett 15:104005. https://doi.org/10.1088/1748-9326/abaada

Gan B, Wu L, Jia F, Li S, Cai W, Nakamura H, Alexander MA, Miller AJ (2017) On the response of the Aleutian low to greenhouse warming. J Climate 30:3907-3925. https://doi.org/10.1175/ JCLI-D-15-0789.1

Gervais M, Shaman J, Kushnir Y (2019) Impacts of the North Atlantic warming hole in future climate projections: Mean atmospheric circulation and the North Atlantic jet. J Climate 32:2673-2689. https://doi.org/10.1175/JCLI-D-18-0647.1

Gong T, Luo D (2017) Ural blocking as an amplifier of the Arctic sea ice decline in winter. J Climate 30:2639-2654. https://doi.org/10. 1175/JCLI-D-16-0548.1

Hand R, Keenlyside NS, Omrani NE, Bader J, Greatbatch RJ (2019) The role of local sea surface temperature pattern changes in shaping climate change in the North Atlantic sector. Clim Dyn 52:417438. https://doi.org/10.1007/s00382-018-4151-1

Harvey BJ, Shaffrey LC, Woollings TJ (2015) Deconstructing the climate change response of the Northern Hemisphere wintertime storm tracks. Clim Dyn 45:2847-2860. https://doi.org/10.1007/ s00382-015-2510-8

Hazeleger W, Severijns C, Semmler T (2010) EC-Earth: a seamless earth system prediction approach in action. Bull Amer Meteor Soc 91:1357-1363. https://doi.org/10.1175/2010BAMS2877.1

Horel JD, Wallace JM (1981) Planetary-scale atmospheric phenomena associated with the Southern Oscillation. Mon Wea Rev 109:813-829

Hoskins BJ, Valdes PJ (1990) On the existence of storm-tracks. J Atmos Sci 47:1854-1864

Hu X, Taylor PC, Cai M, Yang S, Deng Y, Sejas S (2017) Intermodel warming projection spread: Inherited traits from control climate diversity. Sci Rep 7:4300. https://doi.org/10.1038/ s41598-017-04623-7

Hu X, Fan H, Cai M, Sejas SA, Taylor P, Yang S (2020) A less cloudy picture of the inter-model spread in future global warming projections. Nat Comm 11:4472. https://doi.org/10.1038/ s41467-020-18227-9

Kang SM, Frierson DMW, Held IM (2009) The tropical response to extratropical thermal forcing in an idealized GCM: The importance of radiative feedbacks and convective parameterization. J Atmos Sci 66:2812-2827

Lau NC (1988) Variability of the observed midlatitude storm tracks in relation to low-frequency changes in the circulation pattern. $\mathrm{J}$ Atmos Sci 45:2718-2743

Lau NC, Ploshay JJ (2013) Model projections of the changes in atmospheric circulation and surface climate over North America, the North Atlantic, and Europe in the twenty-first century. J Climate 26:9603-9620. https://doi.org/10.1175/JCLI-D-13-00151.1

Manzini E, Yu. Karpechko A, Anstey J et al (2014) Northern winter climate change: Assessment of uncertainty in CMIP5 projections related to stratosphere-troposphere coupling. J Geophys Res, 119, 7979-7998. https://doi.org/10.1002/2013JD021403

Neale RB, Richter J, Park S, Lauritzen PH, Vavrus SJ, Rasch PJ, Zhang M (2013) The mean climate of the Community Atmosphere Model (CAM4) in forced SST and fully coupled experiments. J Climate 26:5150-5168. https://doi.org/10.1175/JCLI-D-12-00236.1

Ogawa F, Keenlyside N, Gao Y et al (2018) Evaluating impacts of recent Arctic sea-ice loss on the northern hemisphere winter climate change. Geophys Res Lett 45:3255-3263. https://doi.org/10. 1002/2017GL076502

Omrani NE, Keenlyside NS, Bader J, Manzini E (2014) Stratospheric key for wintertime atmospheric response to warm Atlantic decadal conditions. Clim Dyn 42:649-663. https://doi.org/10.1007/ s00382-013-1860-3

Omrani NE, Bader J, Keenlyside NS, Manzini E (2016) Tropospherestratosphere response to large-scale North Atlantic ocean variability in an atmosphere/ocean coupled model. Clim Dyn 46:13971415. https://doi.org/10.1007/s00382-015-2654-6

Oudar T, Cattiaux J, Douville H (2020) Drivers of the Northern extratropical eddy-driven jet change in CMIP5 and CMIP6 models. Geophys Res Lett 47: e2019GL086695. https://doi.org/10.1029/ 2019GL086695

Peings Y, Magnusdottir G (2014) Response of the wintertime Northern Hemisphere atmospheric circulation to current and projected Arctic sea ice decline: a numerical study with CAM5. J Climate 27:244-264. https://doi.org/10.1175/JCLI-D-13-00272.1

Peings Y, Labe ZM, Magnusdottir G (2021) Are 100 ensemble members enough to capture the remote atmospheric response to $+2^{\circ} \mathrm{C}$ Arctic sea ice loss. J Climate 34:3751-3769. https://doi.org/10. 1175/JCLI-D-20-0613.1

Sardeshmukh PD, Hoskins BJ (1988) The generation of global rotational flow by steady idealized tropical divergence. J Atmos Sci 45:1228-1251

Schneider T, Bischoff T, Haug GH (2014) Migrations and dynamics of the intertropical convergence zone. Nature 513:45-53. https:// doi.org/10.1038/nature13636

Screen JA, Simmonds I, Deser C, Tomas R (2013) The atmospheric response to three decades of observed Arctic sea ice loss. J Climate 26:1230-1248. https://doi.org/10.1175/JCLI-D-12-00063.1

Screen JA, Deser C, Smith DM et al (2018) Consistency and discrepancy in the atmospheric response to Arctic sea-ice loss across climate models. Nat Geoscience 11:155-163. https://doi.org/10. 1038/s41561-018-0059-y

Shaw TA, Baldwin M, Barnes EA et al (2016) Storm track processes and the opposing influence of climate change. Nat Geoscience 9:656-664. https://doi.org/10.1038/ngeo2783

Shepherd TG (2014) Atmospheric circulation as a source of uncertainty in climate change projections. Nat Geoscience 7:703-708. https:// doi.org/10.1038/NGEO2253

Svendsen L, Keenlyside N, Bethke I, Gao Y, Omrani NE (2018) Pacific contribution to the early twentieth century warming in the Arctic. Nat Clim Change 8:793-797. https://doi.org/10.1038/ s41558-018-0247-1

Takaya K, Nakamura H (2001) A formulation of a phase-independent wave-activity flux for stationary and migratory quasi-geostrophic 
eddies on a zonally-varying basic flow. J Atmos Sci 58:608-627. https://doi.org/10.1175/1520-0469(2001)058\%3c0608:AFOAPI\% 3e2.0.CO

Taylor PC, Cai M, Hu A, Meehl J, Washington W, Zhang GJ (2013) A decomposition of feedback contribution to polar warming amplification. J Climate 26:7023-7043. https://doi.org/10.1175/ JCLI-D-12-00696.1

Vial J, Dufresne JL, Bony S (2013) On the interpretation of intermodel spread in CMIP5 climate sensitivity estimates. Clim Dyn 41:3339-3362. https://doi.org/10.1007/s00382-013-1725-9

Woollings T, Gregory JM, Pinto JG, Reyers M, Brayshaw DJ (2012) Response of the North Atlantic storm track to climate change shaped by ocean-atmosphere coupling. Nat Geoscience 5:313317. https://doi.org/10.1038/NGEO1438

Yim BY, Min HS, Kug JS (2016) Inter-model diversity in jet stream changes in relation to Arctic climate in CMIP5. Clim Dyn 47:235248. https://doi.org/10.1007/s00382-015-2833-5
Yin JH (2005) A consistent poleward shift of the storm tracks in simulations of 21st century climate. Geophys Res Lett 32:L1870. https://doi.org/10.1029/2005GL023684

Zappa G, Shepherd TG (2017) Storylines of atmospheric circulation change for European climate impact assessment. J Climate 30:6561-6577. https://doi.org/10.1175/JCLI-D-16-0807

Zappa G, Pithan F, Shepherd TG (2018) Multimodel evidence for an atmospheric circulation repsonse to Arctic sea ice loss in the CMIP5 future projections. Geophys Res Lett 45:1011-1019. https://doi.org/10.1002/2017GL076096

Zhang P, Wu Y, Simpson IR, Smith KL, Zhang X, De B, Callaghan P (2018) A stratospheric pathway linking a colder Siberia to Barents-Kara sea ice loss. Sci Advances 4:eaat6025. https://doi.org/ 10.1126/sciadv.aat6025

Publisher's Note Springer Nature remains neutral with regard to jurisdictional claims in published maps and institutional affiliations. 